\title{
Two Dimensional Gel Electrophoresis in Cancer Proteomics
}

\author{
Soundarapandian Kannan', Mohanan V. Sujitha ${ }^{1}$, \\ Shenbagamoorthy Sundarraj ${ }^{1}$ and Ramasamy Thirumurugan ${ }^{2}$ \\ 1 Proteomics and Molecular Cell Physiology Lab \\ Department of Zoology, Bharathiar University, Coimbatore \\ ${ }^{2}$ Department of Animal Science, Bharathidasan University, Tiruchirappalli
}

India

\section{Introduction}

Two-dimensional electrophoresis (2-DE) is a powerful and widely used method for the analysis of complex protein mixtures extracted from cells, tissues, or other biological samples. This technique sort's protein according to two independent properties in two discrete steps: the first-dimension step, isoelectric focusing (IEF), separates proteins according to their isoelectric points (pI); the second-dimension step, SDS-polyacrylamide gel electrophoresis (SDS-PAGE), separates proteins according to their molecular weights (Mr, relative molecular weight). Each spot on the resulting two-dimensional array corresponds to a single protein species in the sample. Thousands of proteins can thus be separated, and information such as the protein pI, the apparent molecular weight, and the amount of each protein obtained. The separation of proteins by 2-DE dates back to the 1950s. The first 2-DE technique was developed by Smithies and Poulik in 1956 and O'Farrell, 1975 and Klose, 1975 significantly modified this method to elucidate protein profile. In the original technique, the first-dimension separation was performed in carrier ampholyte-containing polyacrylamide gels cast in narrow tubes.

The power of 2-DE as a biochemical separation technique has been recognized virtually since its introduction. Its application, however, has become significant only in the last few years because of a number of developments. The introduction of immobilized $\mathrm{pH}$ gradients and Immobiline ${ }^{\mathrm{TM}}$ reagents brought superior resolution and reproducibility to firstdimension IEF. Based on this concept, Görg et al., 1989 and Gorg, 1991 developed the currently employed 2-D technique, where carrier ampholyte-generated $\mathrm{pH}$ gradients have been replaced with immobilized $\mathrm{pH}$ gradients and tube gels replaced with gels supported by a plastic backing. New mass spectrometry techniques have been developed that allow rapid identification and characterization of very small quantities of peptides and proteins extracted from single 2-D spots. More powerful, less expensive computers and software are now available, rendering thorough computerized evaluations of the highly complex 2-D patterns economically feasible. Data about entire genomes (or substantial fractions thereof) for a number of organisms are now available, allowing rapid identification of the gene encoding a protein separated by 2 -DE. The World Wide Web provides simple, direct access 
to spot pattern databases for the comparison of electrophoresis results and genome sequence databases for assignment of sequence information.

A large and growing application of 2-DE in "proteome analysis." Proteome analysis is "the analysis of the entire Protein complement expressed by a genome". The analysis involves the systematic separation, identification, and quantification of many proteins simultaneously from a single sample. Two-dimensional electrophoresis is used e due to its unparalleled ability to separate thousands of proteins simultaneously. Two-dimensional electrophoresis is also unique in its ability to detect post- and co-translational modifications, which cannot be predicted from the genome sequence. Applications of 2-DEinclude proteome analysis, cell differentiation, and detection of disease markers, monitoring therapies, drug discovery, cancer research, purity checks, and microscale protein purification.

"Proteomics" is the large-scale screening of the proteins of a cell, organism or biological fluid, a process, which requires stringently controlled steps of sample preparation, 2-DE, image detection and analysis, spot identification, and database searches. Moreover, Proteomics studies lead to the molecular characterization of cellular events associated with cancer progression, cellular signaling, developmental stages etc. Proteomics studies of clinical tumor samples have led to the identification of cancer-specific protein markers, which provide a basis for developing new methods for early diagnosis and early detection and clues to understand the molecular characterization of cancer progression. A keystone of conventional proteomics is high-resolution 2D gel electrophoresis followed by protein identification using mass spectrometry.

As a technique with high-flux and high resolution, proteomics has been widely applied in proteome analysis of tumors. The onset and development of the tissues and cells can be detected at the entire protein level through analyzing the differential expression of proteins. The combination of 2-DE and mass spectrometry can be used to identify differential proteins between tumor cells and normal original cells, and these differential proteins imply a large quantity of biological information. Some of the special proteins are special markers of tumors. The most consistently successful proteomic method is the combination of twodimensional gel electrophoresis (2DE) for protein separation, visualization, and mass spectrometric (MS) identification of proteins using peptide mass fingerprints and tandem MS peptide sequencing.

The experiments form the basis of proteomics, and present significant challenges in data analysis, storage and querying. The core technology of proteomics is 2-DE. At present, there is no other technique that is capable of simultaneously resolving thousands of proteins in one separation procedure. The replacement of classical first-dimension carrier ampholyte $\mathrm{pH}$ gradients with well-defined immobilized $\mathrm{pH}$ gradients has resulted in higher resolution, improved inter-laboratory reproducibility, higher protein loading capacity, and an extended basic $\mathrm{pH}$ limit for 2-DE. With the increased protein capacity, micropreparative 2-DE has accelerated spot identification by mass spectrometry and Edman sequencing. The remarkable improvements in 2-DE resulting from immobilized $\mathrm{pH}$ gradient gels, together with convenient new instruments for IPG-IEF, will make critical contributions to advances in proteome analysis.

A comprehensive understanding of protein-protein interactions is an important step in our quest to understand how the information contained in a genome is put into action. Although a number of experimental techniques can report on the existence of a protein- 
protein interaction, very few can provide detailed structural information. NMR spectroscopy is one of these, and in recent years several complementary NMR approaches, including residual dipolar couplings and the use of paramagnetic effects, have been developed that can provide insight into the structure of protein-protein complexes.

Two-dimensional gel electrophoresis for separation of complex protein samples coupled with mass spectrometry for protein identification has been used to analyze protein expression patterns for many sample types. Inherent in the use of this technique is information on not only full-length protein expression, but expression of modified, splice variant, cleavage product, and processed proteins. Any protein modification that leads to a change in overall protein charge and/or molecular weight (MW) will generate a different spot on the 2-DE. Modification specific staining can identify whether a specific posttranslational modification is responsible for the shift, and mass spectrometry can potentially identify the source of isoelectric point $(\mathrm{pI})$ and/or MW differences. Due to the lack of complete coverage for a protein's amino acid sequence using either matrix-assisted laser desorption/ionization mass spectrometry (MALDI-MS) or high-performance liquid chromatography (HPLC) tandem mass spectrometry (LC-MS/MS), there has been limited success in using MS to identify isoforms and post-translational modifications. While the theoretical MW is often slightly higher than the MW of the fully processed protein due to cleavage of signal and pro-peptides, there can also be post-translational modifications that increase the protein's gel MW. Thus, an exploration into the causes of the difference in the theoretical MW and the MW as seen in the gel can yield information about the state of the protein. When the gel MW of a given protein is significantly lower than the calculated weight, the gel spot represents a protein fragment. The extent to which proteins are present as fragments or variants in tissues and fluids has not been determined, but the combination of 2-DE, Western blotting, and mass spectrometry-based protein identification makes such analyses possible. Two-dimensional gel electrophoresis of human mammary tissue, followed by immune blotting, resulted in multiple spots at significantly differing molecular weights. The function of protein fragments is dependent on activation processes and localization properties. This Chapter will be critically analyzed as per the contents given in the synopsis with up-to-date informations.

\section{Overview of experimental design}

\subsection{Experimental design}

\subsubsection{Sample preparation}

Efficient and reproducible sample preparation methods are a key to successful 2-DE (Rabilloud 1999, Macri et al. 2000, Molloy 2000). Sample preparation methods range from extraction with simple solubilization solutions to complex mixtures of chaotropic agents, detergents, and reducing agents. Sample preparation can include enrichment strategies for separating protein mixtures into reproducible fractions.

An effective sample preparation procedure will:

1. Reproducibly solubilize proteins of all classes, including hydrophobic proteins

2. Prevent protein aggregation and loss of solubility during focusing

3. Prevent postextraction chemical modification, including enzymatic or chemical degradation of the protein sample 
4. Remove or thoroughly digest nucleic acids and other interfering molecules

5. Yield proteins of interest at detectable levels, which may require the removal of interfering abundant proteins or nonrelevant classes of proteins

Most protein mixtures will require some experimentation to determine optimum conditions for 2-D PAGE. Variations in the concentrations of chaotropic agents, detergents, ampholytes, and reducing agents can dramatically affect the 2-D pattern.

\subsubsection{Solubilization}

Solubilization of proteins is achieved by the use of chaotropic agents, detergents, reducing agents, buffers, and ampholytes. These are chosen from a small list of compounds that meet the requirements, both chemically and electrically, for compatibility with the technique of IEF in IPG strips. The compounds chosen must not increase the ionic strength of the solution, to allow high voltages to be applied during focusing without producing high currents. Thorough discussion of solubilization methods, including new variations, can be found in several books (Pennington and Dunn 2001, Rabilloud 2000).

\subsubsection{Chaotropic agents}

Urea is the most commonly used chaotropic agent in sample preparation for 2-D PAGE. Thiourea can be used to help solubilize many otherwise intractable proteins. Urea and thiourea disrupt hydrogen bonds and are used when hydrogen bonding causes unwanted aggregation or formation of secondary structures that affect protein mobility. Urea is typically used at $8 \mathrm{M}$. Thiourea is weakly soluble in water, but is more soluble in high concentrations of urea, so a mixture of $2 \mathrm{M}$ thiourea and 5-8 $\mathrm{M}$ urea is used when strongly chaotropic conditions are required (Rabilloud 1998).

\subsubsection{Detergents}

Detergents are added to disrupt hydrophobic interactions and increase solubility of proteins at their pI. Detergents must be nonionic or zwitterionic to allow proteins to migrate according to their own charges. Some proteins, especially membrane proteins, require detergents for solubilization during isolation and to maintain solubility during focusing. Ionic detergents such as SDS are not compatible with IEF, but can be used with concentrated samples in situations where the SDS can be unbound from the proteins by IEF-compatible detergents that compete for binding sites. Nonionic detergents such as octylglucoside, and zwitterionic detergents such as CHAPS and its hydroxyl analog, CHAPSO, can be used. CHAPS, CHAPSO, or octylglucoside concentrations of $1-2 \%$ are recommended (Rabilloud 1999). New detergents are emerging that have great potential in proteomics, including SB $3-$ 10 and ASB-14 (Chevallet et al. 1998). Some proteins may require detergent concentrations as high as $4 \%$ for solubility (Hermann et al. 2000).

\subsubsection{Carrier ampholytes}

A fundamental challenge with IEF is that some proteins tend to precipitate at their pI. Even in the presence of detergents, certain samples may have stringent salt requirements 
to maintain the solubility of some proteins. Salt should be present in a sample only if it is an absolute requirement, and then only at a total concentration less than $40 \mathrm{mM}$. This is problematic since any salt included will be removed during the initial high-current stage of focusing. Salt limits the voltage that can be achieved without producing high current, increasing the time required for focusing. Proteins that require salt for solubility are subject to precipitation once the salt is removed. Carrier ampholytes sometimes help to counteract insufficient salt in a sample. They are usually included at a concentration of $\leq 0.2 \%(\mathrm{w} / \mathrm{v})$ in sample solutions for IPG strips. High concentrations of carrier ampholytes will slow down IEF until they are focused at their pI, since they carry current and hence limit voltage. Some researchers have increased resolution by varying the ampholyte composition.

\subsubsection{Reducing agents}

Reducing agents such as dithiothreitol (DTT) or tributylphosphine (TBP) are used to disrupt disulfide bonds. Bond disruption is important for analyzing proteins as single subunits. DTT is a thiol reducing agent added in excess to force equilibrium toward reduced cysteines. At $50 \mathrm{mM}$ it is effective in reducing most cystines, but some proteins are not completely reduced by this treatment. If the concentration of DTT is too high it can affect the $\mathrm{pH}$ gradient since its $\mathrm{pKa}$ is around 8 . TBP is a much more effective reducing agent than DTT. It reacts to reduce cystines stoichiometrically at low millimolar concentrations (Herbert et al. 1998). It is chemically more difficult to handle than DTT, but Bio-Rad has solved this problem by supplying it in a form safe for shipping and lab use.

\subsubsection{Prefractionation}

Reducing the complexity of the sample loaded on a 2-D gel can increase the visibility of minor proteins. Techniques such as differential extraction (Molloy et al. 1998), subcellular fractionation (Taylor et al. 2000, Morel et al. 2000), chromatography (Fountoulakis et al. 1999), or prefocusing in a preparative IEF device such as the Rotofor ${ }^{\circledR}$ system (Masuoka et al. 1998, Nilsson et al. 2000) have been used to reduce the complexity of samples.

\subsubsection{Removal of albumin and IgG}

The isolation of lower-abundance proteins from serum or plasma is often complicated by the presence of albumin and immunoglobulin $\mathrm{G}(\mathrm{IgG})$. Albumin is the most abundant protein $(\sim 60-70 \%)$ in serum and IgG is the second most abundant protein $(10-20 \%)$. These two proteins effectively act as major contaminants, masking the presence of many co-migrating proteins, as well as limiting the amount of total serum protein that can be resolved on a 2-D gel. In the past, removal of albumin and IgG usually required separate chromatography methodologies for each of the two species. Now, Bio-Rad's Aurum ${ }^{\mathrm{TM}}$ serum protein kit allows selective binding and simultaneous removal of both albumin and IgG from serum or plasma samples prior to 2-DE.

\subsubsection{Sequential extraction}

One method for reducing sample complexity is the basis of the ReadyPrep ${ }^{\mathrm{TM}}$ sequential extraction kit. This protocol takes advantage of solubility as a third independent means 
of protein separation. Proteins are sequentially extracted in increasingly powerful solubilizing solutions. More protein spots are resolved by applying each solubility class to a separate gel, thereby enriching for particular proteins while simplifying the 2-D patterns in each gel. An increase in the total number of proteins is detected using this approach (Molloy et al. 1998).

\subsubsection{Removal of DNA}

The presence of nucleic acids, especially DNA, interferes with separation of proteins by IEF. Under denaturing conditions, DNA complexes are dissociated and markedly increase the viscosity of the solution, which inhibits protein entry and slows migration in the IPG. In addition, DNA binds to proteins in the sample and causes artifactual migration and streaking. The simplest method for removal of DNA is enzymatic digestion. Adding endonuclease to the sample after solubilization at high $\mathrm{pH}(40 \mathrm{mM}$ Tris) allows efficient digestion of nucleic acids while minimizing the action of contaminating proteases. The advantage of the endonuclease method is that sample preparation can be achieved in a single step, by the addition of the enzyme prior to loading the first-dimension IPG.

\subsubsection{Protein load}

The amount of protein applied to an IPG strip can range from several micrograms to $1 \mathrm{mg}$ or more (Bjellqvist et al. 1993a). Some of the factors affecting the decision of how much protein to load are:

a. Subsequent analysis. Enough of the protein of interest must be loaded for it to be analyzed. With the Ready Gel® mini system (7 cm IPG), detection of moderately abundant proteins in complex mixtures with Coomassie Brilliant Blue R-250 dye requires on the order of $100 \mu \mathrm{g}$ total protein. With the same load, many low-abundance proteins can be detected with more sensitive stains such as silver or SYPRO Ruby protein gel stain.

b. The purpose of the gel. If the gel is being run solely for the sake of getting a good image of well-resolved proteins for comparative studies or for publication, the protein load would be the minimum amount that is stainable.

c. The abundance of the proteins of interest. If the purpose is to study low-copy-number proteins, a large mass of a protein mixture might be loaded (Wilkins et al. 1998).

d. The complexity of the sample. A highly complex sample containing many proteins of widely varying concentrations might require a compromise load so that highabundance proteins don't obscure low-abundance proteins. By enriching a sample for specific types of proteins using prefractionation techniques, each individual protein will be at a higher relative concentration, which means that enough material can be loaded for detection of low-abundance constitutents.

e. $\mathrm{pH}$ range of IPG strip. In general, larger amounts of total protein can be loaded on a narrow-range IPG strip. Only the proteins with a $\mathrm{pI}$ within the strip $\mathrm{pH}$ range will be represented within the second-dimension gel.

\subsection{The first dimension: Isoelectric Focusing (IEF)}

\subsubsection{Isoelectric point (pl)}

Differences in proteins' $\mathrm{pI}$ are the basis of separation by IEF. The $\mathrm{pI}$ is defined as the $\mathrm{pH}$ at which a protein will not migrate in an electric field and is determined by the number and 
types of charged groups in a protein. Proteins are amphoteric molecules. As such, they can carry positive, negative, or zero net charge depending on the $\mathrm{pH}$ of their local environment. For every protein there is a specific $\mathrm{pH}$ at which its net charge is zero; this is its pI. Proteins show considerable variation in $\mathrm{pI}$, although $\mathrm{pI}$ values usually fall in the range of $\mathrm{pH} 3-12$, with the majority falling between $\mathrm{pH} 4$ and $\mathrm{pH}$ 7. A protein is positively charged in solution at $\mathrm{pH}$ values below its $\mathrm{pI}$ and negatively charged at $\mathrm{pH}$ values above its $\mathrm{pI}$.

\subsubsection{IEF}

When a protein is placed in a medium with a $\mathrm{pH}$ gradient and subjected to an electric field, it will initially move toward the electrode with the opposite charge. During migration through the $\mathrm{pH}$ gradient, the protein will either pick up or lose protons. As it migrates, its net charge and mobility will decrease and the protein will slow down. Eventually, the protein will arrive at the point in the $\mathrm{pH}$ gradient equal to its $\mathrm{pI}$. There, being uncharged, it will stop migrating. If this protein should happen to diffuse to a region of lower $\mathrm{pH}$, it will become protonated and be forced back toward the cathode by the electric field. If, on the other hand, it diffuses into a region of $\mathrm{pH}$ greater than its $\mathrm{pI}$, the protein will become negatively charged and will be driven toward the anode. In this way, proteins condense, or are focused, into sharp bands in the $\mathrm{pH}$ gradient at their individual characteristic $\mathrm{pI}$ values. Focusing is a steady-state mechanism with regard to $\mathrm{pH}$. Proteins approach their respective $\mathrm{pI}$ values at differing rates but remain relatively fixed at those $\mathrm{pH}$ values for extended periods. By contrast, proteins in conventional electrophoresis continue to move through the medium until the electric field is removed. Moreover, in IEF, proteins migrate to their steady state positions from anywhere in the system.

\subsubsection{IPG strips}

A stable, linear, and reproducible $\mathrm{pH}$ gradient is crucial to successful IEF. IPG strips offer the advantage of gradient stability over extended focusing runs (Bjellqvist et al. 1982). IPG strips are much more difficult to cast than carrier ampholyte gels (Righetti 1983); however, IPG strips are commercially available, for example as ReadyStrip ${ }^{\mathrm{TM}}$ IPG strips. $\mathrm{pH}$ gradients for IPG strips are created with sets of acrylamido buffers, which are derivatives of acrylamide containing both reactive double bonds and buffering groups. The general structure is $\mathrm{CH} 2=\mathrm{CH}-\mathrm{CO}-\mathrm{NH}-\mathrm{R}$, where $\mathrm{R}$ contains either a carboxyl [-COOH] or a tertiary amino group (e.g., $\mathrm{N}(\mathrm{CH} 3) 2$ ). These acrylamide derivatives are covalently incorporated into polyacrylamide gels at the time of casting and can form almost any conceivable $\mathrm{pH}$ gradient (Righetti 1990).

\subsubsection{Choice of $\mathrm{pH}$ gradient ranges}

Use of broad-range strips ( $\mathrm{pH} 3-10)$ allows the display of most proteins in a single gel. With narrow-range and micro-range overlapping gradient strips, resolution is increased by expanding a small $\mathrm{pH}$ range across the entire width of a gel. Since many proteins are focused in the middle of the $\mathrm{pH}$ range 3-10, some researchers use nonlinear (NL) gradients to better resolve proteins in the middle of the $\mathrm{pH}$ range and to compress the width of the extreme $\mathrm{pH}$ ranges at the ends of the gradients. However, overlapping narrow-range and micro-range linear IPG strips can outperform a nonlinear gradient and display more spots 
per sample. This result is due to the extra resolving power from use of a narrower pI range per gel. Use of overlapping gradients also allows the ability to create "cyber" or composite gels by matching spots from the overlapping regions using imaging software.

\subsubsection{IPG strip (2-D array) size}

The $17 \mathrm{~cm}$ IPG strips and large-format gels have a large area to resolve protein spots; however, they take a long time to run. Using a mini system instead of, or as a complement to, a large gel format can provide significant time savings. A mini system is perfect for rapid optimization of sample preparation methods. Switching to a large format then allows thorough assessment of a complex sample and identification of proteins of interest. In many cases, a mini system consisting of narrow-range IPG strips can then be used to focus in on the proteins of interest. Throughput of the 2-D process is a consideration in choosing gel size. The ability to cast or run 12 gels at a time in any of 3 size formats is very useful in gathering proteomic results. In some cases, mini systems $(7 \mathrm{~cm}$ ReadyStrip IPG strips with Mini-PROTEAN® 3 format gels, or $11 \mathrm{~cm}$ ReadyStrip IPG strips with Criterion ${ }^{\mathrm{TM}}$ precast gels) can completely replace large 2-D systems, providing speed, convenience, and ease in handling. The availability of narrow and micro overlapping $\mathrm{pH}$-range ReadyStrip IPG strips can increase the effective width of $\mathrm{pI}$ resolution more than 5-fold after accounting for overlapping regions. When 3 narrow-range overlapping ReadyStrip IPG strips are used with the Criterion system, the resolution in the first dimension is increased from 11 to $26 \mathrm{~cm}$. When micro-range strips are used, the resolution in the first dimension is expanded from 11 to $44 \mathrm{~cm}$.

\subsubsection{Estimation of pl}

The $\mathrm{pI}$ of a protein can be estimated by comparing the position of the protein spot of interest to the position of known proteins or standards separated across the same $\mathrm{pH}$ gradient (Bjellqvist et al. 1993b, Garfin 2000). ReadyStrip IPG strips contain linear gradients, so the pI of an unknown protein can be estimated by linear interpolation relative to proteins of known pI.

\subsubsection{Sample application}

Commercial IPG strips are dehydrated and must be rehydrated to their original gel thickness $(0.5 \mathrm{~mm})$ before use. This allows flexibility in applying sample to the strips. There are 3 methods for sample loading: passive in-gel rehydration with sample, active in-gel rehydration with sample, or cup loading of sample after IPG rehydration. Introducing the sample while the strips are rehydrating is the easiest method. In some specific instances, it is best to rehydrate the strips and then apply sample through sample cups while current is applied.

\subsubsection{Sample application during rehydration}

For both active and passive rehydration methods, the sample is introduced to the IPG strip at the time of rehydration. As the strips hydrate, proteins in the sample are absorbed and distributed over the entire length of the strip (Sanchez et al. 1997). In the case of active rehydration, a very low voltage is applied during rehydration of the strips. Proteins enter 
the gel matrix under current as well as by absorption. The PROTEAN IEF cell has preprogrammed methods designed to accommodate active rehydration. Active rehydration is thought to help large proteins enter the strip by applying electrical "pull". Because the voltage is applied before all the solution and proteins are absorbed into the gel, the $\mathrm{pH}$ of a protein's environment will be the $\mathrm{pH}$ of the rehydration buffer, and the protein will move according to its mass-to charge ratio in that environment. Thus, small proteins with a higher mobility have a higher risk of being lost from the strip. With passive rehydration, proteins enter the gel by absorption only. This method allows efficient use of equipment since strips can be rehydrated in sample rehydration trays while other samples are being focused in the IEF cell.

Whether the strips are hydrated actively or passively, it is very important that they be incubated with sample for at least $11 \mathrm{hr}$ prior to focusing. This allows the high molecular weight proteins time to enter the gel after the gel has become fully hydrated and the pores have attained full size. These sample application methods work because IEF is a steady-state technique, so proteins migrate to their $\mathrm{pI}$ independent of their initial positions.

The advantages of this approach are:

a. Sample application is simple (Görg et al. 1999)

b. Sample application during rehydration avoids the problem of sample precipitation, which often occurs with cup loading (Rabilloud 1999)

c. Shorter focusing times can be used because the sample proteins are in the IPG strip prior to IEF

d. Very large amounts of protein can be loaded using this method

\subsubsection{Sample application by cup loading}

Cup loading can be beneficial in the following cases (Cordwell et al. 1997, Görg et al. 2000):

- When samples contain high levels of DNA, RNA, or other large molecules, such as cellulose

- For analytical serum samples that have not been treated to remove albumin

- When running basic IPG strips; e.g., pH 7-10

- For samples that contain high concentrations of glycoproteins

Because of its relative difficulty and tendency toward artifacts, cup loading should be avoided if possible. When loading the protein sample from a cup, the IPG strips must be rehydrated prior to sample application. The IPG strips can be rehydrated in a variety of ways.

The rehydration tray is recommended although IPG strips are often rehydrated in 1 or $2 \mathrm{ml}$ pipettes that have been sealed at both ends with Para film. Sample volumes of up to $100 \mu \mathrm{l}$ can be loaded later onto each gel strip using a sample cup.

\subsubsection{Power conditions and resolution in IEF}

During an IEF run, the electrical conductivity of the gel changes with time, especially during the early phase. When an electrical field is applied to an IPG at the beginning of an IEF run, the current will be relatively high because of the large number of charge carriers present. 
As the proteins and ampholytes move toward their pIs, the current will gradually decrease due to the decrease in the charge on individual proteins and carrier ampholytes. The $\mathrm{pH}$ gradient, strip length, and the applied electrical field determine the resolution of an IEF run. According to both theory and experiment, the difference in pI between two adjacent IEFresolved protein bands is directly proportional to the square root of the $\mathrm{pH}$ gradient and inversely proportional to the square root of the voltage gradient at the position of the bands (Garfin 2000). Thus, narrow $\mathrm{pH}$ ranges and high-applied voltages yield high resolution in IEF. The highest resolution can be achieved using micro-range IPG strips and an electrophoretic cell, such as the PROTEAN IEF cell, capable of applying high voltages. IEF runs should always be carried out at the highest voltage compatible with the IPG strips and electrophoretic cell. However, high voltages in electrophoresis are accompanied by large amounts of generated heat. The magnitude of the electric field that can be applied and the ionic strength of the solutions that can be used in IEF are limited. Thin gels are better able to dissipate heat than thick ones and are therefore capable of withstanding the high voltage that leads to higher resolution. Also, at the completion of focusing, the current drops to nearly zero since the carriers of the current have stopped moving. The PROTEAN IEF cell is designed to provide precise cooling, allowing the highest possible voltages to be applied. (A default current limit of $50 \mu \mathrm{A}$ per strip is intended to minimize protein carbamylation reactions in urea sample buffers. This limit can be increased to $99 \mu \mathrm{A}$ per strip.)

Consistent and reproducible focusing requires that the time integral of voltage (volt-hours) be kept consistent. It is usually necessary to program IEF runs to reach final focusing voltages in stages. This approach clears ionic constituents in the sample from the IPG strips while limiting electrical heating of the strips. The PROTEAN IEF cell allows for multistep runs at durations set by time or volt-hours. The number of volt-hours required to complete a run must be determined empirically. A more complex sample in terms of number of proteins or even a different sample buffer might require increased volt-hours. The time needed to achieve the programmed volt-hours depends on the $\mathrm{pH}$ range of the IPG strip used as well as sample and buffer characteristics. If different strips are run at the same time, the electrical conditions experienced by individual strips will be different, perhaps exposing some strips to more current than desired, since the total current limit is averaged over all strips in a tray.

\subsection{The second dimension: SDS-PAGE}

\subsubsection{Protein separation by molecular weight (MW)}

Second-dimension separation is by protein mass, or MW, using SDS-PAGE. The proteins resolved in IPG strips in the first dimension are applied to second-dimension gels and separated by MW perpendicularly to the first dimension. The pores of the second-dimension gel sieve proteins according to size because dodecyl sulfate coats all proteins essentially in proportion to their mass. The net effect is that proteins migrate as ellipsoids with a uniform negative chargeto- mass ratio, with mobility related logarithmically to mass (Garfin 1995).

\subsubsection{Gel composition}

Homogeneous (single-percentage acrylamide) gels generally give excellent resolution of sample proteins that fall within a narrow MW range. Gradient gels have two advantages: 
they allow proteins with a wide range of MW to be analyzed simultaneously, and the decreasing pore size along the gradient functions to sharpen the spots.

\subsubsection{Single-percentage gels}

The percentage of acrylamide, often referred to as $\% \mathrm{~T}$ (total percentage of acrylamide plus crosslinker) determines the pore size of a gel. Most protein separations use 37.5 parts acrylamide to 1 part bis-acrylamide (bis). Some researchers substitute piperazine bisacrylamide (PDA), which can reduce silver staining background and give higher gel strength. If the total percentage of acrylamide plus crosslinker is higher, the smaller is the pore size. A suitable $\% \mathrm{~T}$ can be estimated from charts of mobility for proteins of different MW.

\subsubsection{Gradient gels}

Gradient gels are cast with acrylamide concentrations that increase from top to bottom so that the pore size decreases as proteins migrate further into the gels. As proteins move through gradient gels from regions of relatively large pores to regions of relatively small pores, their migration rates slow. Small proteins remain in gradient gels much longer than they do in single-percentage gels that have the same average $\% \mathrm{~T}$, so both large and small molecules may be resolved in the same gel. This makes gradient gels popular for analysis of complex mixtures that span wide MW ranges. A gradient gel, however, cannot match the resolution obtainable with a properly chosen single concentration of acrylamide. A good approach is to use gradient gels for estimates of the complexities of mixtures. A proteomics experiment might start out with an $8-16 \% \mathrm{~T}$ gradient for global comparison. After interesting regions of the 2-D array have been identified, a new set of single-percentage gels may be run to study a particular size range of proteins. It is simplest and often most cost and labor effective to purchase commercially available precast gradient gels.

\subsubsection{Precast gels}

High-quality precast gels are preferred for high-throughput applications. They provide savings in time and labor, and the precision-poured gradients result in reproducibility among runs. Precast gels differ from handcast gels in that they are cast with a single buffer throughout and without SDS. During storage, different buffers in the stacking and resolving gels would mingle without elaborate means to keep them separate, and thus have no practical value. In addition, because the sample contains SDS, and the dodecyl sulfate ion in the cathode buffer moves faster than the proteins in the gel, keeping them saturated with the detergent, precast gels are made without SDS.

\subsubsection{Transition from first to second dimension}

The transition from first-dimension to second-dimension gel electrophoresis involves two steps: equilibration of the resolved IPG strips in SDS reducing buffer, and embedding of the strip on the top of the second-dimension gel. Proper equilibration simultaneously ensures that proteins are coated with dodecyl sulfate and that cysteines are reduced and alkylated. The equilibrated IPG strips are placed on top of the gel and fixed with molten agarose solution to ensure good contact between the gel and the strip. 


\subsubsection{Second dimension and high throughput}

Since the first dimension can be run in batches of 12-24 strips at a time, it is desirable to run the same number of samples in the second dimension. Precast gels ensure high reproducibility among samples and help reduce the work involved in running large numbers of samples. Alternatively, gels can be hand cast 12 at a time under identical conditions with multi-casting chambers. The Dodeca cells save time, space, and effort, and help to ensure that gels are run under the same electrical conditions for highest throughput and reproducibility.

\subsubsection{MW estimation}

The migration rate of a polypeptide in SDS-PAGE is inversely proportional to the logarithm of its MW. The larger the polypeptide, the more slowly it migrates in a gel. MW is determined in SDS-PAGE by comparing the migration of protein spots to the migration of standards. Plots of log MW versus the migration distance are reasonably linear. Gradient SDS-PAGE gels can also be used to estimate MW. In this case, log MW is proportional to log $(\% \mathrm{~T})$. With linear gradients, $\% \mathrm{~T}$ is proportional to distance migrated, so the data can be plotted as log MW vs. log (migration distance). Standard curves are actually sigmoid. The apparent linearit of a standard curve may not cover the full MW range for a given protein mixture in a particular gel. However, log MW varies sufficiently slowly to allow accurate MW estimates to be made by interpolation, and even extrapolation, over relatively wide ranges (Garfin 1995). Mixtures of standard proteins with known MW are available from BioRad in several formats for calibrating the migration of proteins in electrophoretic gels. Standards are available unstained, prestained, or with tags for development with various secondary reagents (useful when blotting). Standards can be run in a reference well, attached to the end of a focused IPG strip by filter paper, or directly embedded in agarose onto the second-dimension gel

\subsection{Detection of proteins in gels}

\subsubsection{Guidelines for detection of proteins in gels}

Gels are run for either analytical or preparative purposes. The intended use of the gel determines the amount of protein to load and the means of detection. It is most common to make proteins in gels visible by staining them with dyes or metals. Each type of protein stain has its own characteristics and limitations with regard to the sensitivity of detection. Sometimes proteins are transferred to membranes by western blotting to be detected by immunoblotting, glycoprotein analysis, or total protein stain. If the purpose of gel electrophoresis is to identify low-abundance proteins (e.g., low-copy-number proteins in a cell extract, or contaminants in a purification scheme), then a high protein load (0.1-1 $\mathrm{mg} / \mathrm{ml}$ ) and a high-sensitivity stain, such as silver or a fluorescent stain, should be used (Corthals et al. 2000). When the intention is to obtain enough protein for use as an antigen or for sequence analysis, then a high protein load should be applied to the gel and the proteins visualized with a staining procedure that does not fix proteins in the gel. Quantitative comparisons require the use of stains with broad linear ranges of detection. The sensitivity that is achievable in staining is determined by: 1) the amount of stain that binds to the proteins; 2) the intensity of the coloration; 3) the difference in coloration between stained 
proteins and the residual background in the body of the gel (the signal-to-noise ratio). Unbound stain molecules can be washed out of the gels without removing much stain from the proteins. All stains interact differently with different proteins (Carroll et al. 2000). No stain will universally stain all proteins in a gel in proportion to their mass. The only observation that seems to hold for most stains is that they interact best with basic amino acids. For critical analysis, replicate gels should be stained with two or more different stains. Of all stains available, colloidal Coomassie Blue (Bio-Safe ${ }^{\mathrm{TM}}$ Coomassie) appears to stain the broadest spectrum of proteins. It is instructive, especially with 2-D PAGE gels, to stain a colloidal Coomassie Blue-stained gel with silver or to stain a fluorescently stained gel with colloidal Coomassie Blue or silver. Very often, this double staining procedure will show a few differences between the protein patterns. It is most common to stain gels first with Coomassie Blue or a fluorescent stain, and then restain with silver. However, the order in which the stains are used does not seem to be important, as long as the gels are washed well with high-purity water between stains.

\subsubsection{Coomassie blue staining}

Coomassie Brilliant Blue R-250 is the most common stain for protein detection in polyacrylamide gels. Coomassie Brilliant Blue R-250 and G-250 are wool dyes that have been adapted to stain proteins in gels. The " $R$ " and " $G$ " designations indicate red and green hues, respectively. Coomassie R-250 requires on the order of $40 \mathrm{ng}$ of protein per spot for detection. Absolute sensitivity and staining linearity depend on the proteins being stained. The staining solution also fixes most proteins in gels. Bio-Safe Coomassie stain is made with Coomassie Brilliant Blue G-250. Bio-Safe Coomassie stain is a ready-touse, single-reagent protein stain. Sensitivity can be down to $10 \mathrm{ng}$, and greater contrast is achieved by washing the gel in water after staining. Used stain can be disposed of as nonhazardous waste and the procedure does not fix proteins in the gel.

\subsubsection{SYPRO ruby fluorescent staining}

SYPRO Ruby protein gel stain has desirable features that make it popular in highthroughput laboratories. It is an endpoint stain with little background staining (high signalto noise characteristics) and it is sensitive and easy to use. SYPRO Ruby protein stain does not detect nucleic acids. SYPRO Ruby protein stain is sensitive to 1-10 ng and can be linear over 3 orders of magnitude. It is compatible with high through put protocols and downstream analysis, including mass spectrometry and Edman sequencing (Patton 2000). It also allows detection of glycoproteins, lipoproteins, low MW proteins, and metalloproteins that are not stained well by other stains. This fluorescent stain is easily visualized with simple UV or blue-light transilluminators, as well as by the Molecular Imager FX ${ }^{\mathrm{TM}}$ Pro Plus multiimager and VersaDoc ${ }^{\mathrm{TM}}$ imaging systems.

\subsubsection{Silver staining}

Two popular methods for silver staining are recommended for 2-D analysis. They are based on slightly different chemistries but have similar sensitivities for protein. Bio-Rad's silver stain kit, based on the method of Merril et al. (1981), can be as much as 100 times more sensitive than Coomassie Blue R-250 dye staining and allows visualization of 
heavily glycosylated proteins in gels. Protein spots containing 10-100 ng of protein can be easily seen. Proteins in gels are fixed with alcohol and acetic acid, then oxidized in a solution of potassium dichromate in dilute nitric acid, washed with water, and treated with silver nitrate solution. Silver ions bind to the oxidized proteins and are subsequently reduced to metallic silver by treatment with alkaline formaldehyde. Color development is stopped with acetic acid when the desired staining intensity has been achieved. This method is not compatible with mass spectroscopic analysis since the oxidative step changes protein mass. The Silver Stain Plus stain from Bio-Rad requires only one simultaneous staining and development step and is based on the method developed by Gottlieb and Chavko (1987). Proteins are fixed with a solution containing methanol, acetic acid, and glycerol, and washed extensively with water. The gels are then soaked in a solution containing a silverammine complex bound to colloidal tungstosilicic acid. Silver ions transfer from the tungstosilicic acid to the proteins in the gel by means of an ion exchange or electrophilic process. Formaldehyde in the alkaline solution reduces the silver ions to metallic silver to produce the images of protein spots. The reaction is stopped with acetic acid when the desired intensity has been achieved. Because silver ions do not accumulate in the bodies of gels, background staining is light. Since this method lacks an oxidizing step, visualization of heavily glycosylated proteins and lipoproteins can be less sensitive than with the Merril stain. This method is better for use in proteomics when the end goal is identification by mass spectrometric analysis.

\subsection{Image acquisition and analysis}

\subsubsection{Image acquisition instruments}

Before 2-D gels can be analyzed with an image evaluation system, they must be digitized. The most commonly used devices are camera systems, densitometers, phosphor imagers, and fluorescence scanners. All of Bio-Rad's imaging systems are seamlessly integrated with PDQuest ${ }^{\mathrm{TM}}$ software, and they can export and import images to and from other software via TIFF files.

\subsubsection{Densitometry}

Densitometers compare the intensity of a light beam before and after attenuation by a sample. The GS-800 ${ }^{\mathrm{TM}}$ calibrated imaging densitometer has been customized for analysis of gels, autoradiograms, and blots. The transmittance and true reflectance capabilities allow accurate scans of samples that are either transparent (gels and film) or opaque (blots). It provides high-quality imaging to resolve close spots and a variable resolution feature to preview and crop images. Wet 2-D gels may be scanned with red, green, and blue color CCD technology on the watertight platen.

\subsubsection{Storage phosphor and fluorescence scanners}

Digitization of 2-D gels stained with fluorescent dyes or radioactive compounds requires specific imaging systems (Patton 2000). The Molecular Imager FX' ${ }^{\mathrm{TM}}$ Pro Plus system is flexible and expandable. 2-D gels of radiolabled proteins can be imaged using a Kodak phosphor screen more rapidly and accurately than with film. Popular proteomic fluorescent stains, including SYPRO Ruby protein gel and blot stains and SYPRO Orange protein gel 
stain can be imaged with single-color and multicolor fluorescence via direct laser excitation. This system permits detection of almost any fluorophore that is excited in the visible spectrum. The internal laser and external laser options allow optimal excitation of singlecolor or multicolor fluorescent samples. Computer-controlled, user-accessible filter wheels have eight filter slots, allowing detection of many multicolor combinations of dyes (Gingrich et al. 2000).

\subsubsection{Computer-assisted image analysis of 2-D electrophoretic gels}

Computer-assisted image analysis software is an indispensable tool for the evaluation of complex 2-D gels. It allows:

a. Storage and structuring of large amounts of collected experimental image data

b. Rapid and sophisticated analysis of experimental information

c. Supplementation and distribution of data among labs

d. Establishment of 2-D-protein data banks

Image analysis systems deliver error-fee comprehensive qualitative and quantitative data from a large number of 2-D gels (Miller 1989). PDQuest software from Bio-Rad is a popular analysis tool. Gel analysis of digitized gel images includes spot detection, spot quantitation, gel comparison, and statistical analysis. PDQuest software has the further advantage of seamless integration with any of Bio-Rad's image acquisition instruments, as well as the ability to control the ProteomeWorks ${ }^{\mathrm{TM}}$ spot cutter. The advanced annotation feature can be used to label spots with text, URL links, document links, or mass spectrometry data.

\subsubsection{Spot detection and spot quantitation}

Before the software automatically detects the protein spots of a 2-D gel, the raw image data are corrected and the gel background is subtracted. The process is executed with simple menus and "wizards." PDQuest software models protein spots mathematically as 3-D Gaussian distributions and uses the models to determine absorption maxima. This enables automatic detection a resolution of merged spots. Following this procedure, spot intensities are obtained by integration of the Gaussian function. The mathematical description of the spots is used both for data reduction and for increasing evaluation speed, since reevaluation of data after an image change takes only fractions of a second. The hit rate of automatic spot detection is highly dependent on the quality of the 2-D gels. Correction capabilities of PDQuest software can be used to add undetected spots to the list of spots or to delete spots that arise from gel artifacts.

\subsubsection{Gel comparison}

The next step in 2-D gel evaluation is the identification of proteins that are present in all gels of a series. This task is made difficult primarily because of inherent irreproducibility in gels, which affects the positions of spots within a gel series. Gel analysis software must detect minor shifts in individual spot position within the gel series. Many software packages for automatic gel comparison are created with the assumption that the relative positions of spots are altered only slightly relative to each other, and allocate the spots on this basis. Prior to automatic gel comparison, PDQuest software selects the best 2-D gel of a gel series as a reference or standard gel and compares all other 2-D gels to this gel. Proteins in a gel 
series that are not present in the reference gel are added manually so that the reference gel will include all proteins of a gel series.

Before the software can detect and document matching of different spots, a number of landmarks, or identical spots in the gel series, must be manually identified. The landmarking tool speeds the process by making "best guess" assignments of landmark spots to images in the gel series. With PDQuest software, it is possible to simultaneously display up to 100 enlarged details of 2-D gels on the screen. This simultaneous display of all 2-D gels of a test series enables rapid and error-free determination of the fixed points. Using the landmarks, the image analysis software first attempts to compare all spots lying very near these fixed points and then uses the matched spots as starting points for further comparisons. Thus, the entire gel surface is systematically investigated for the presence or absence of matching spots in a gel series. The results of the automatic gel comparison require verification, as does automatic spot detection.

Two tools assist this verification process in PDQuest: Either identical protein spots are labeled with matching letters and allocated section by section, or the deviations in the spot positions of a particular 2-D gel can be displayed as lines that show spot shifts in comparison to the reference gel.

\subsubsection{Data analysis}

With PDQuest software, all gels of an experiment are viewed as a unit. To compare gels from different experiments, the reference images are compared. In such comparisons, each spot is automatically assigned a number so that identical spots have identical numbers. Experimental data can also be analyzed statistically both parametric and nonparametric tests are available.

\subsection{Identification and characterization of 2-D protein spots}

\subsubsection{Sequence data from 2-D gels}

2-DE has the virtually unique capability of simultaneously displaying several hundred gene products. 2-D gels are an ideal starting point for protein chemical identification and characterization. Peptide mass fingerprint or sequence data can be derived following 2-DE with mass spectrometry or amino acid sequence analysis (Eckerskorn et al. 1988, Ducret et al. 1996). The sensitivity of currently available instruments makes 2-DE an efficient "preparative" analytical method. Most current protein identification depends on mass spectrometry of proteins excised from gels or blots.

\subsubsection{Integration of image analysis with automated spot cutting}

Image analysis software obtains quantitative and qualitative information about the proteins in a sample, and stores the information in files, which may also contain additional annotations. The ProteomeWorks ${ }^{\mathrm{TM}}$ spot cutter expands the capabilities of proteome labs by integrating PDQuest ${ }^{\mathrm{TM}}$ image analysis software. The image analysis files acquired by PDQuest direct automated spot cutting. Excised protein spots are deposited into microtiter plates ready for further automated processing. PDQuest software tracks the protein spots through spot cutting and protein identification. Downstream protein spot identifications are 
generally obtained from peptide mass fingerprint analysis using mass spectrometry. The ProteomeWorks spot cutter is a precision instrument with a small benchtop footprint. It is fully automatic to increase throughput and minimize the amount of hands-on time spent excising protein spots. The spot cutter individually excises even overlapping spots for unique identification.

\subsubsection{Automated protein digestion}

The ProteomeWorks spot cutter eliminates the first of two bottlenecks for excision and enzymatic digestion of protein spots. Driven by PDQuest software, it enables automated spot excision and deposition of cut gel spots into microtiter plate wells. Isolated proteins from the gel pieces are then digested to release peptides for detailed sequence analysis by mass spectrometry, leading to protein identification. Excised gel spots can be robotically destained, chemically modified (reduced and alkylated), and digested in preparation for either MALDITOF-MS or ESI-MS with the Micromass MassPREP station. Each process is executed under fully automated software control with a range of standard protocols enabling high throughput and flexibility. Manual protein digestion is a tedious, time-consuming process that is subject to variability and keratin contamination. Automation of this process with the Mass PREP station eliminates a significant bottleneck for high-throughput protein identification.

Operational features of the MassPREP station include a variable temperature control for optimized reduction, alkylation, and digestion of proteins, and onboard cooling capabilities for reagents and peptide digests to ensure reproducible digestion results. The station employs a variety of sample cleaning technologies (MassPREP targets and Millipore ZipTip pipet tips) to prepare peptide digests prior to automated deposition of samples onto a M@LDI or MassPREP target plate. Contamination of peptide samples is also minimized with the MassPREP clean air enclosure.

\subsubsection{Rapid, high-throughput protein identification by MALDI-TOF-MS}

Peptide mass fingerprinting of protein digest products using matrix assisted laser desorption ionization time of flight mass spectrometry (MALDI-TOF-MS) provides an ideal method for protein identification when samples have been separated by 2-D PAGE. The M@LDI HT is one of a new generation of networked "2-D gel-MS" analyzers for highthroughput protein identification. M@LDI HT is the primary MS data acquisition device of the ProteomeWorks system, and features a fully automated target plate auto-changer for increased throughput. Networking enables distribution of data capture, protein assignment, and result presentation functions of ProteinLynx Global SERVER software within a secure clientserver architecture, maximizing computing power to quickly identify proteins. The M@LDI HT enables automated acquisition of optimized mass spectra and the derivation of monoisotopic peptide mass fingerprint information. Interrogation of multiple FASTA databases using Global SERVER software following capture of MS results provides rapid identification of proteins that fit the samples' peptide mass fingerprint, along with a confidence score indicating the validity of the identifications. Following MS identification, peptide mass fingerprint spectra and all of the identification results are available through electronic reports. In addition, protein identification results are seamlessly integrated with the gel image in PDQuest software. Using this system, the working time to process data 
from spot cutting to protein digestion to MS analysis and image annotation is reduced by over $50 \%$ compared to manual processing of gel samples, with a corresponding reduction in error. All of the instrumentation and software in this process is part of the integrated ProteomeWorks system, a set of powerful tools for proteomic analysis.

\subsubsection{Advanced protein characterization with ESI-LC-MS and MALDI-TOF}

MALDI-TOF MS provides an ideal high-throughput solution for protein identification; however, where protein identity is ambiguous, known databases must be searched with a higher degree of sequence information. The Micromass Q-Tof family of MS-MS instruments incorporates quadrupole/ orthogonal acceleration time-of-flight (Q/oa-TOF) technology, enabling exact mass measurement, and acquisition of the highest-level peptide sequence information for de novo sequencing and BLAST analyses. Protein digest samples in microtiter plates, prepared with the MassPREP station, can be transferred directly to the Micromass CapLC (capillary HPLC) system for automated injection into the Q-Tof micro for integrated LC-MS-MS under MassLynx software control. The capability for MS to MS-MS switching "on the fly" with the Q-Tof family of instruments maximizes the amount of amino acid sequence information that can be generated with these instruments. MassSeq software also provides the capacity for automated de novo amino acid sequencing based on the MS results.

\subsubsection{DE in identification of bladder carcinoma protein marker (Calreticulin)}

Susumu Kageyama et al., 2004 screened proteins as tumor markers for bladder cancer by proteomic analysis (2DE) of cancerous and healthy tissues and investigated the diagnostic accuracy of one such marker, Calreticulin (CRT) in urine.

They have produced two important findings in their experiments. The first is that increased production of CRT in bladder cancer tissue which was confirmed by proteome profiling by 2DE. Furthermore, we detected two isoforms of CRT, and full-length CRT which was more useful than cleaved CRT for distinguishing bladder cancer from healthy tissue.

In their study, although visual comparison of 2DE gels of TCC (transitional cell carcinoma) and noncancerous urothelium showed similar expression profiles, 15 protein spots (U-1 to U-15) were more intense in TCC samples (Fig. 1). They identified 10 of the proteins by use of a peptide mass fingerprinting method. One spot among them, with an apparent mass of 55 $\mathrm{kDa}$ and $\mathrm{pI}$ of 4.3, was identified as CRT (spot U-2 in Fig. 1 A). From NH2-terminal amino acid sequencing, 10 amino acids were sequenced (EPAVYFKEQF), and they were identical to residues 1-10 of mature human CRT according to the sequence homology search.

Further, to validate the 2DE finding of increased production of full-length CRT in bladder cancer tissue, they performed quantitative Western blot analysis in cancerous and healthy tissue using anti-COOH-terminus antibody. They compared CRT band intensities for 22 cancerous with 10 noncancerous tissues. For band quantification, they defined the CRT band derived from a total of $1 \mu \mathrm{g}$ of heat-shocked HeLa cell extract as $1.0 \mathrm{unit} / \mu \mathrm{g}$ of protein. The mean (SD) concentrations in cancerous and healthy tissue were $1.0(0.4)$ and $0.4(0.3)$ units $/ \mu$ g of protein, respectively (Mann-Whitney $U$-test, $P=0.0003$; Fig. 2). Among these tissue samples, six pairs of cancerous and noncancerous specimens were obtained from the bladders of patients who had undergone radical cystectomy. CRT concentrations were higher in all cancer tissues compared with the corresponding healthy urothelium. 
To confirm the presence of isoforms of CRT, they performed two-dimensional Western blotting with two different antibodies: monoclonal antibody FMC75, which was produced against recombinant human CRT; and a polyclonal antibody that was produced using synthesized peptides of the human CRT COOH terminus (amino acids 388-400) as an immunogen. On Western blots with anti- $\mathrm{COOH}$-terminus antibody, only one of the two spots was visualized, whereas both spots became visible on blots incubated with FMC75 (Fig. 3). One was the same as the 55-kDa (pI 4.3) spot, and the other had an apparent molecular mass of $40 \mathrm{kDa}$ and $\mathrm{pI}$ of 4.5 . This lower molecular- mass spot had the same NH2terminal amino acid sequence as amino acids 1-10 of mature human CRT as shown by amino acid sequencing. Therefore, they suggested that the higher-molecular-mass spot was the full-length form and the other spot was a cleaved form that is truncated elsewhere in the $\mathrm{COOH}$ domain. Production of the full-length CRT in cancer tissue was increased compared with in healthy tissue, but the spots for cleaved CRT in cancerous and healthy urothelium had intensities that were similar and were reproducible on all silverstained 2DE gels.

Subsequently they tried to confirm whether anti-COOH terminus antibody binds to molecules other than full lengt1h CRT and performed immuno-precipitations (Fig. 4). The Western blot of the immuno-precipitate extracted from cancer tissue revealed only one band, and they concluded that anti-COOH-terminus antibody binds specifically to fulllength CRT of $\sim 55 \mathrm{kDa}$. They therefore judged that full-length CRT recognized by anti$\mathrm{COOH}$ terminus antibody is appropriate as a tumor marker.
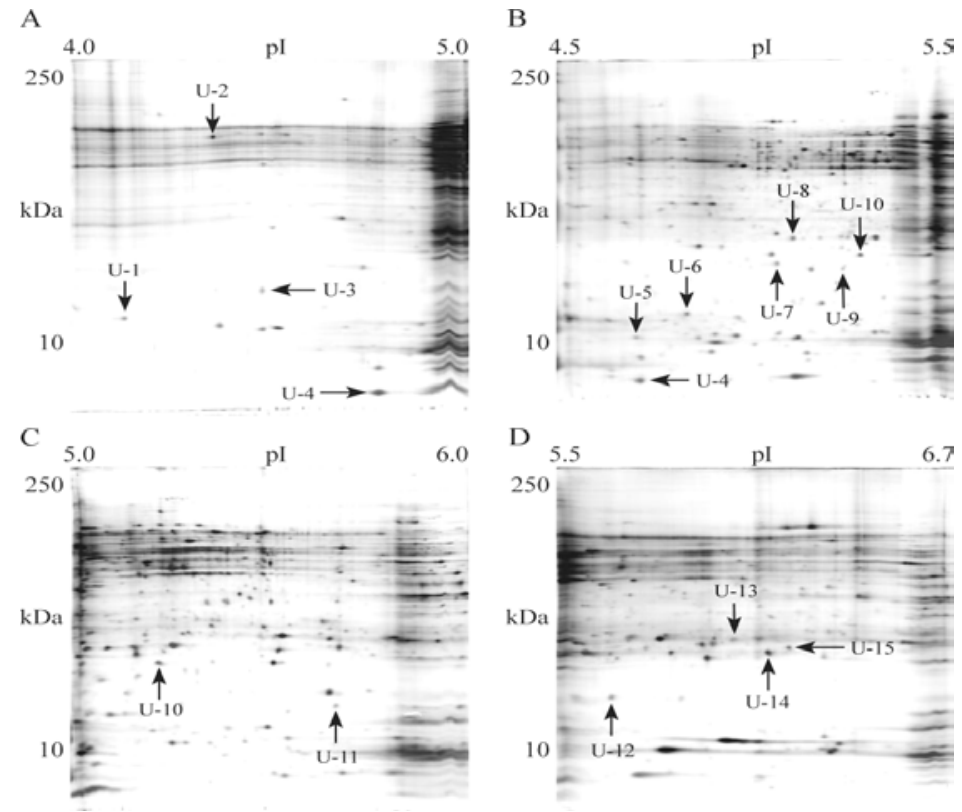

Fig. 1. Silver-stained images of analytical narrow-pH-range 2DE gels of proteins from bladder cancer. (A), pH 4.0-5.0; (B), pH 4.5-5.5; (C), pH 5.0-6.0; (D), pH 5.5-6.7. Arrows indicate spots (U-1 to U-15) containing higher amounts of protein. Spot U-2, $\sim 55 \mathrm{kDa}$ and $\mathrm{pI}$ 4.3 , was confirmed to be CRT by a peptide mass fingerprinting method and NH2-terminal amino acid sequencing. (Source: Susumu Kageyama et al., 2004 Clinical Chemistry, 50: 857-866) 


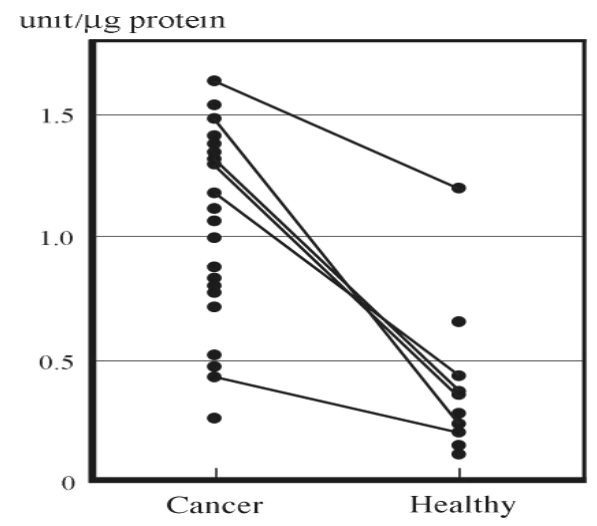

Fig. 2. Quantitative Western blot analysis of cancerous and healthy tissues using anti$\mathrm{COOH}$-terminus antibody. Lines show six pairs of cancerous and healthy specimens obtained from the bladders of patients who had undergone radical cystectomy.(Source: Susumu Kageyama et al., 2004 Clinical Chemistry, 50: 857-866)
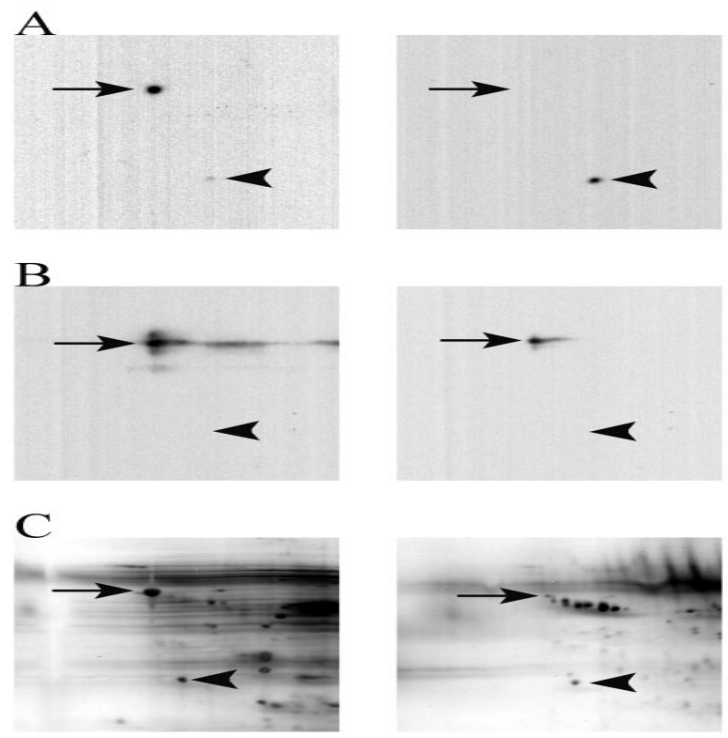

Fig. 3. Close-up sections of two-dimensional Western blot images obtained with two different antibodies, FMC75 $(A)$ and anti-COOH terminus antibody $(B)$, and proteins in silver-stained $\mathrm{pH}$ 4-7 gels $(C)$. Left panels are bladder cancer and right panels are healthy urothelium. Arrows indicate full-length CRT (55 kDa; pI 4.3), and arrowheads indicate cleaved CRT (40 kDa; pI 4.5). These two CRT forms have the same NH2-terminal amino acid sequence (EPAVYFKEQF), but cleaved CRT is considered to lack the $\mathrm{COOH}$ terminus because of no immunoreactivity for anti-COOH-terminus antibody. (Source: Susumu Kageyama et al., 2004 Clinical Chemistry, 50: 857-866) 


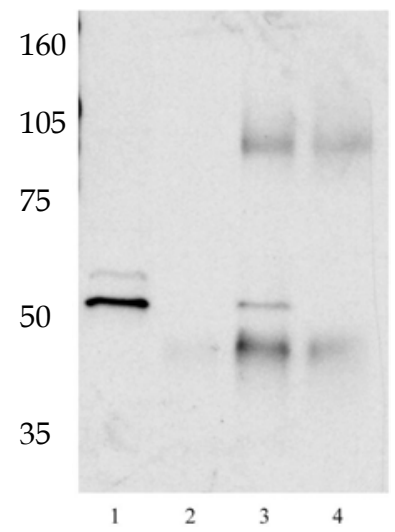

Fig. 4. Western blot with FMC75 antibody. Arrow indicates 55-kDa full-length CRT. Lane 1, total cell lysate; lane 2, extraction from protein A Sepharose beads that did not bind antibody; lane 3, immunoprecipitant eluted from beads binding anti-COOH-terminus antibody; lane 4, immunoprecipitant extracted from beads binding normal rabbit IgG indicates approximate molecular masses. (Source: Susumu Kageyama et al., 2004 Clinical Chemistry, 50: 857-866)

\subsubsection{2-DE in identification of pancreatic carcinoma protein marker}

Leucine-rich alpha-2-glycoprotein is characterized by its unusually high content of leucine, about $17 \%$ by weight. The primary structure of LRG suggests that it may be a membrane associated or membrane-derived protein. Aberrant regulation of LRG has been observed in patients with malignant disease and with virus infection.

Tatsuhiko Kakisaka et al., 2007 examined the plasma LRG expression levels of cancer patients who were not in the acute inflammatory phase. First, they selected cancer patients with normal C-reactive protein (CRP) concentration (Table 1, P6-10) to explore whether the increase in LRG levels paralleled the dynamics of the commonacute phase proteins. Second, they tested plasma from cancer patients with a normal level of CA19-9 a tumor marker commonly used for the diagnosis of pancreatic cancer, to examine the possibility of plasma LRG levels being using in a way complementary to existing tumor markers.

SDS-PAGE/Western blotting using an anti-LRG antibody showed consistent upregulation of LRG in these patients, who were negative for CRP and/or CA19-9, compared with the noncancer bearing healthy donors (Fig. 5). Therefore, increased amounts of LRG may be independent of the regulation of other acute phase proteins and tumor markers. They also examined plasma samples from chronic pancreatitis patients and found that they tended to express lower LRG levels compared with the samples from pancreatic cancer patients. By correlating the expression levels of LRG with clinical information from a large sample set, they hope to validate the utility of LRG as a biomarker to monitor the status of patients. Some plasma samples from pancreatic cancer patients did not express high LRG levels, leading us to suggest that the examination of plasma LRG levels in combination with the existing biomarkers would increase the specificity and sensitivity of the diagnosis. 
Some protein spots on 2D-PAGE gels overlapped across fractions in the anion-exchange chromatography even when they used the step-wise gradient method with system wash between intervals. They considered these overlapping spots to correspond to different isoforms of the same protein, and have therefore counted all protein spots on the 2D-PAGE gels. However, not every differentially expressed protein was considered to be a suitable tumor marker; for example, spots 8 and 11 (transthyretin) were differentially expressed between cancer patients and healthy donors, but they were very minute amounts of the total abundant transthyretin, and it was difficult to extract theseportion of the protein. On the contrary, LRG, which was also differentially expressed between cancer patients and healthy donors, was only expressed in one fraction and was therefore selected as a candidate for a tumor marker of pancreatic cancer.

The use of high-resolution 2D-PAGE with narrow-range IPG gels and large-format second dimension gels could solve this problem to some extent.

\begin{tabular}{|c|c|c|c|c|c|c|}
\hline Case $^{a}$ & Age & Sex & Tumor location & Stage $^{b}$ & CA19-9 (U/ml) & $\mathrm{CRP}(\mathrm{mg} / \mathrm{dl})$ \\
\hline P6 & 56 & Male & Head & IV & 1 & 0.1 \\
\hline P7 & 45 & Female & Body tail & IV & 3698 & 0.1 \\
\hline P8 & 55 & Female & Body & III & $<1$ & $<0.1$ \\
\hline P9 & 58 & Male & Body & IV & 25600 & 0.1 \\
\hline P10 & 65 & Female & Body & III & 804 & $<0.1$ \\
\hline Case $^{\mathrm{a}}$ & Age & Sex & & & & \\
\hline N6 & 53 & Male & & & & \\
\hline N7 & 51 & Female & & & & \\
\hline N8 & 60 & Female & & & & \\
\hline N9 & 59 & Male & & & & \\
\hline N10 & 64 & Female & & & & \\
\hline
\end{tabular}

${ }^{a} \mathrm{P}$ : pancreatic cancer patients, $\mathrm{N}$ : non-cancer bearing healthy donors.

b The Union Internationale Contre le Cancer (UICC) classification [41].

Table 1. Patient informations of validation set 1

\subsubsection{2-DE in identification of human gastric carcinoma protein marker}

Gastric cancer is the second most common cause of cancer deaths worldwide and due to its poor prognosis, it is important that specific biomarkers are identified to enable its early detection. Through 2-D gel electrophoresis and MALDI-TOF-TOF-based proteomics approaches, Chien-Wei Tseng et al., 2011 found that 14-3-3 $\beta$, which was one of the proteins that were differentially expressed by 5 -fluorouracil-treated gastric cancer SC-M1 cells, was up regulated in gastric cancer cells. 14-3-3 $\beta$ levels in tissues and serum were further validated in gastric cancer patients and controls. The results showed that $14-3-3 \beta$ levels were elevated in tumor tissues in comparison to normal tissues, and serum levels in cancer patients were also significantly higher than those in controls (Fig. 6). Elevated serum 14-3-3 $\beta$ levels highly correlated with the number of lymph node metastases, tumor size, and a reduced survival rate. Moreover, over-expression of 14-3-3 $\beta$ enhanced the growth, invasiveness, and migratory activities of tumor cells. Twenty-eight proteins involved in antiapoptosis and tumor progression were also found to be differentially expressed in 14-3-3 $\beta$ overexpressing gastric cancer cells. Overall, these results highlight the significance of 14-3$3 \beta$ in gastric cancer cell progression and suggest that it has the potential to be used as a diagnostic and prognostic biomarker in gastric cancer. 

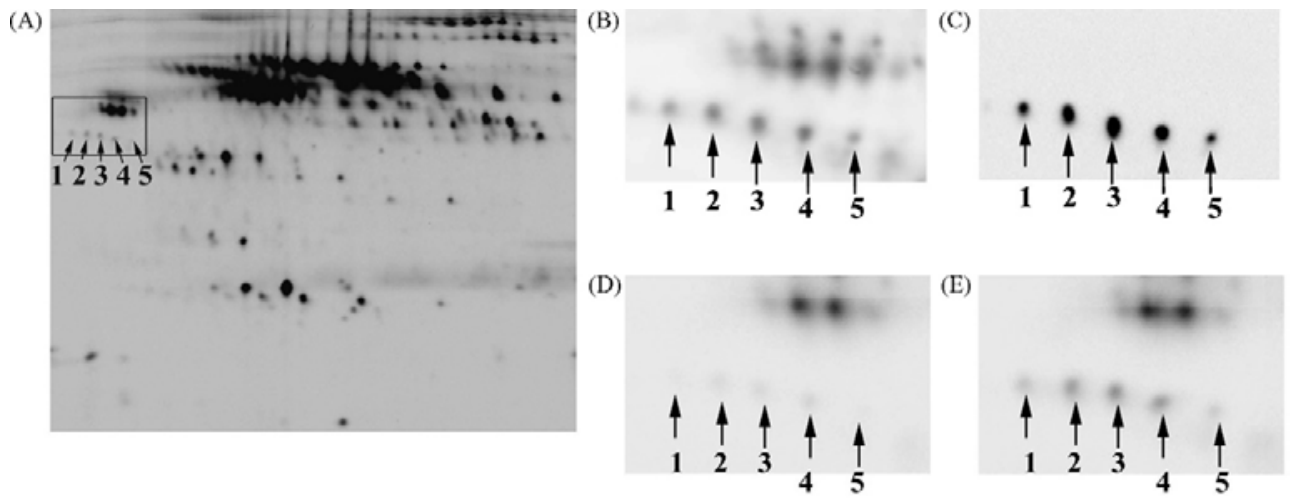

Fig. 5. Elevated level of plasma LRG in pancreatic cancer. The localizations of the five LRG spots are indicated by arrows $1-5$ on the $2 \mathrm{D}$ image of the $150 \mathrm{mM} \mathrm{NaCl}$ sample (A). The boxed area was transferred to a nitrocellulose membrane and scanned with a laser scanner to obtain the LRG spots on the membrane (B). The scanned membrane was reacted with an anti-LRG antibody and the antibody-antigen complexes were detected with an ECL system (C). The fluorescent signals of the LRG spots on the 2D-PAGE gels were compared between non-cancer bearing healthy donors (D) and pancreatic cancer patients (E). (Source: Tatsuhiko Kakisaka et al., 2007 Journal of Chromatography B, 852: 257-267)

\subsubsection{DE in identification of squamous cervical carcinoma protein markers}

Recently, proteomic and genomic approaches to identify tumor markers are undergoing. Hellman and coworkers reported the protein expression patterns in primary carcinoma of the vagina. In relation to HPV, C33A cell line transfected with HPV E7 gene and proteomic and genomic analyses were performed. But, until now, there was no report of SCC in cervix tissues. Prof. W.S. Ahn and his colleagues at Cancer Research Center of The Catholic University of Korea, South Korea contributed much more to understand the significance of 2DGE in diagnosis of cervical cancer. In general, screening in cervical cancer is progressing to find out candidate genes and proteins, which may work as biological markers and play a role in tumor progression. They examined the protein expression patterns of squamous cell carcinoma (SCC) tissues from Korean women using two-dimensional polyacrylamide gel electrophoresis (2-DE) and matrix-assisted laser desorption/ionization-time of fight (MALDI-TOF) mass spectrometer. A total of 35 proteins are detected in SCC. 17 proteins are up regulated and 18 proteins are down-regulated. Among the proteins identified, 12 proteins (pigment epithelium derived factor, annexin A2 and A5, keratin 19 and 20, heat shock protein 27 , smooth muscle protein 22 alpha, alpha-enolase, squamous cell carcinoma antigen 1 and 2, glutathione S-transferase, apolipoprotein a1) are previously known proteins involved in tumor and 21 proteins were newly identified in this study. They concluded that the 2-DE offers total protein expression profiles of SCC tissues and further characterization of proteins that are differentially expressed will give a chance to identify tumor-specific diagnostic markers for SCC (Fig. $7 \& 8$ ). 


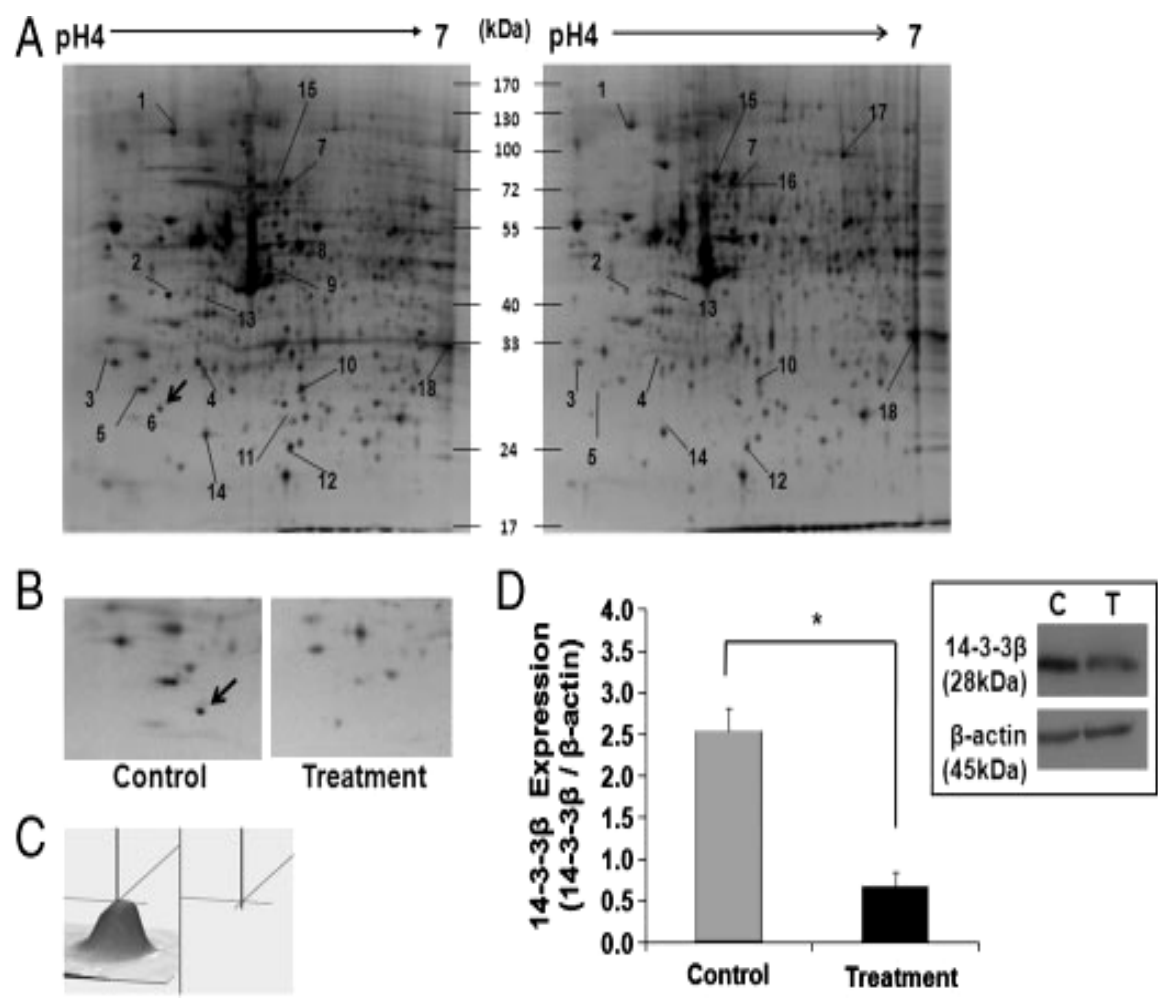

Fig. 6. 14-3-3 $\beta$ is differentially expressed after 5-FU treatment of SC-M1 cells.

(A) Proteins from the 5-FU-treated (right) SC-M1 cells and the untreated control (left) were compared using 2-DE. Enlarged images and 3-D profiles of 14-3-3b on the gels are shown in (B) and (C). (D) 14-3-3 $\beta$ expression was significantly reduced after 5-FU treatment as confirmed by Western blot. (Source: Chien-Wei Tseng et al., 2011 Proteomics, 11:2423-2439)

In addition to cervical cancer, the 2-dimensional polyacrylamide gel electrophoresis (2-DE) has also been used to examine heterogeneity of protein expression in tissues from different tumors such as bladder, breast, colon-rectum, lung, and ovary. The advantage of 2-DE is that the complex protein expression is analyzed qualitatively and quantitatively. 2-DE combined with MALDI-TOF-MS has been applied to identify cancer-specific protein markers. These markers can provide a basis for developing new methods for early diagnosis and treatment. 


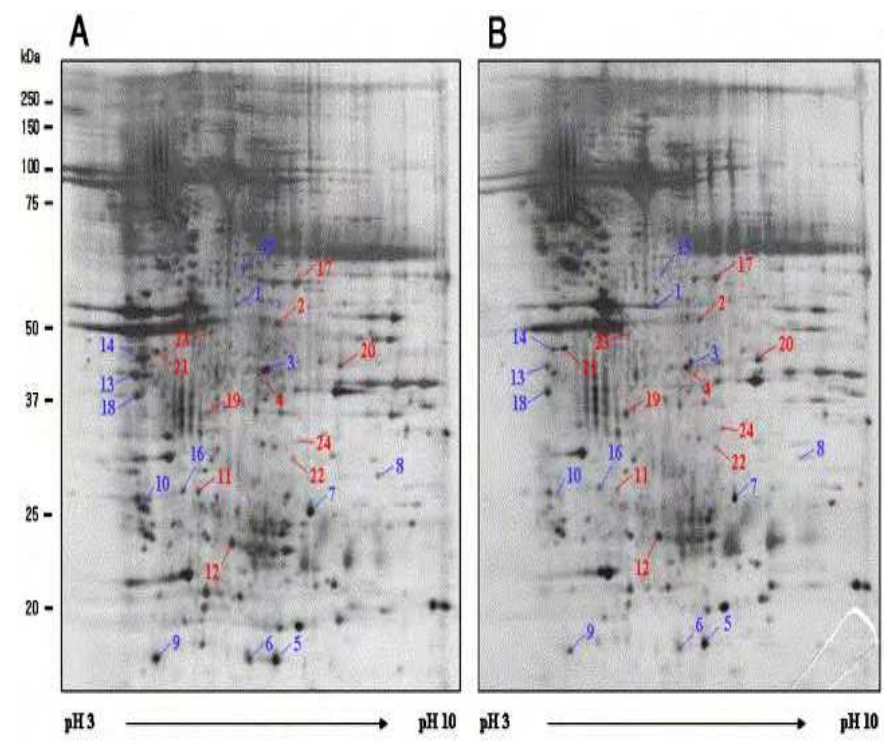

Fig. 7. Comparison of proteome by two-dimensional gel electrophoresis on normal tissues and cervical SCC tissues. Representative examples of 2-DE gels derived from a normal cervix tissue and cervical SCC tissue. Normal cervix (A) and cervical SCC (B) total proteins were separated by 2-DE using IPG strips $\mathrm{pH} 3-10$ in the first and 12\% SDS-PAGE in the second dimension. Identified protein spots are indicated by numbers. Proteins down- (A) or up-regulated (B) in cervical SCC are indicated. (Source: Bae et al., 2005 Gynecologic Oncol., 99: 26-35)

\subsubsection{Breast cancer protein profiling}

Franzen et al., 1997 well documented that the two-dimensional electrophoresis (2-DE) analyses of human breast carcinoma reveals the following observations: (i) Analysis of samples from different areas of the same tumor showed a high degree of similarity in the pattern of polypeptide expression. Similarly, analysis of two tumors and their metastases revealed similar 2-DE profiles. (ii) In contrast, large variations have been observed between different lesions with comparable histological characteristics. Larger differences in polypeptide expression are pointed out in between potentially highly malignant carcinomas and comparisons of less malignant lesions. These differences are in the same order of magnitude as those observed comparing a breast carcinoma to a lung carcinoma. (iii) The levels of all cytokeratin forms resolved (CK7, CK8, CK15, and CK18) were significantly lower in carcinomas compared to fibro adenomas. (iv) The levels of high molecular weight tropo-myosins (1-3) were lower in carcinomas compared to fibro adenomas. The expression of tropomyosin- 1 is 1.7 -fold higher in primary tumors with metastatic spread to axillar lymph nodes compared to primary tumors with no evidence of metastasis $(p<0.05)$. (v) The expression of proliferating cell nuclear antigen (PCNA) and some members of the stress protein family (pHSP60, HSP90, and calreticulin) are higher in carcinomas. We conclude that malignant progression of breast carcinomas results in large heterogeneity in polypeptide expression between different tumors, but that some common themes such as 
decreased expression of cytokeratin and tropomyosin polypeptides can be discerned (Fig. 9 \& 10). (Franzen, et al. 1997 Electrophoresis, 18:582-587.).

A

Normal

Cancer
14-3-3 $\varepsilon$
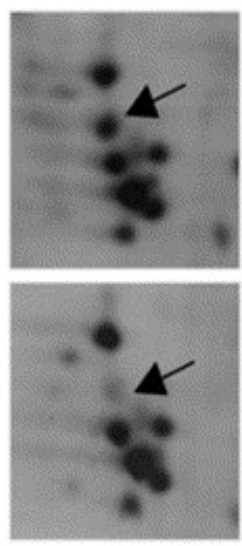

Annexin 1
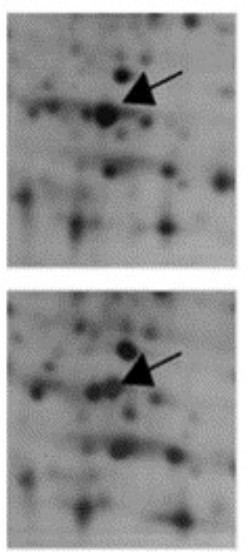

SCCA-2
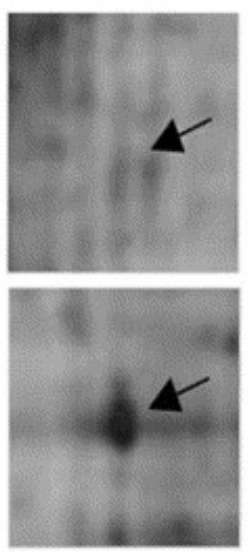

B
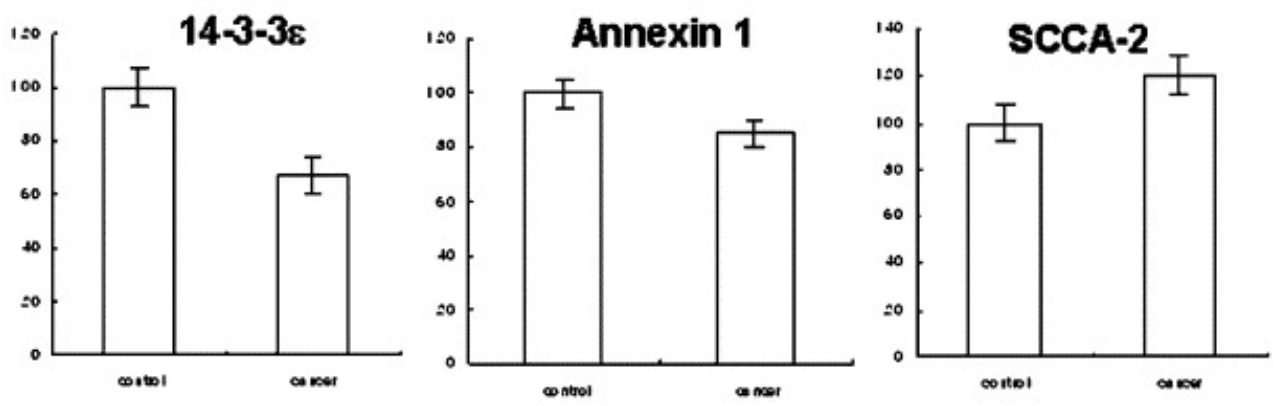

Fig. 8. Protein expression comparisons of normal samples and SCC samples. Up- and downregulated proteins (14-3-3e, annexin A1, and SCCA-2) were selected and magnified gel images were presented (A). From the PDQuest 2-D software quantification, the expression difference was statistically meaningful (P value < 0.05) (B). (Source: Bae et al., 2005

Gynecologic Oncol., 99: 26-35)

The same gel was post-stained with SyproRuby dye (right panel). $100 \mu \mathrm{g}$ of each lysate from serum-starved cells were analyzed on a $9-16 \%$ gradient gel. Circles represent differentially expressed proteins detectable by both methods. Arrows represent spots detected by SyproRuby but not Cy dye labeling. $B$, the shift in molecular weight between the modified and unmodified proteins was visualized by image overlaying. The DIGE image (Blue) was overlaid with the SYPRO image (Red). 


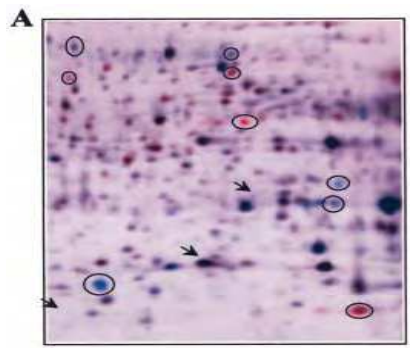

Cy Dye Image

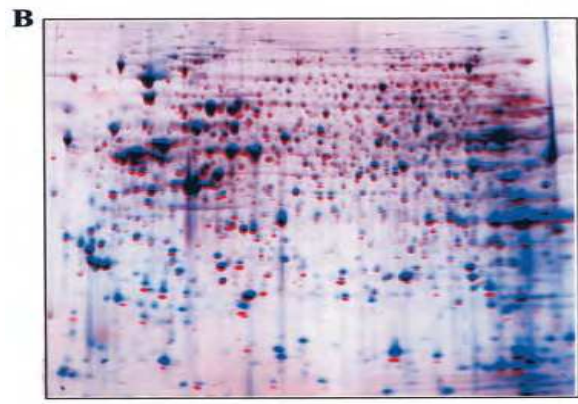

Red: Post-stained image with Sypro Ruby Blue: Merged image of $\mathrm{Cy} 3+\mathrm{Cy} 5$
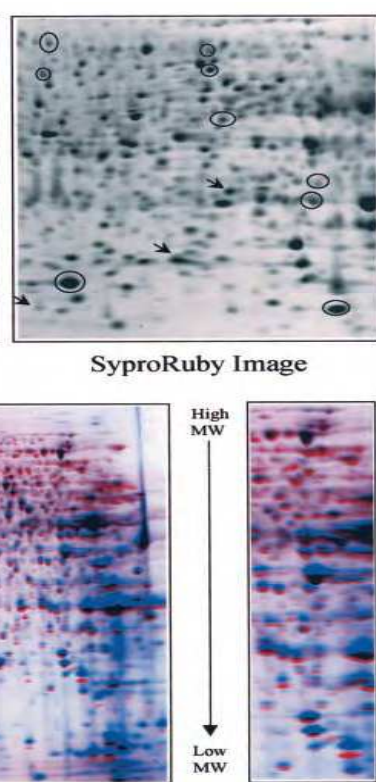

Fig. 9. Sensitivity of 2D-DIGE and compatibility with SYPRO gel staining. A, comparison of 2D-DIGE imaging and SyproRuby poststaining. Merged Cy dye image of HB4a lysate labeled with Cy3 (red) and HBc3.6 lysate labeled with Cy5 (blue) (left panel).

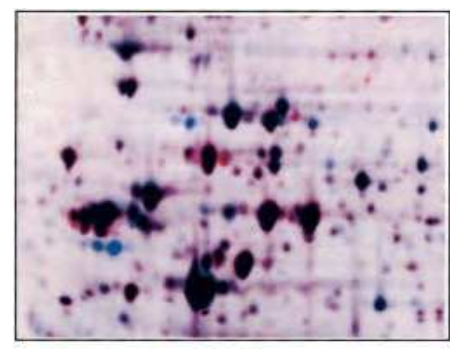

Gel 1

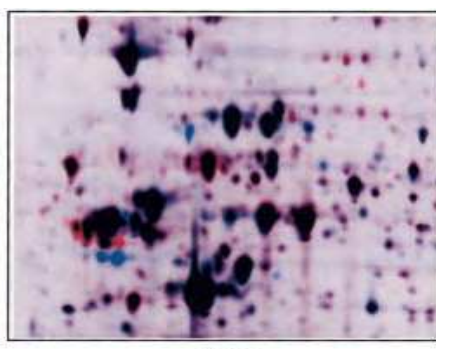

Gel 2

Fig. 10. 2D-DIGE is a reproducible detection method. Duplicate samples of HB4a and $\mathrm{HBc} 3.6$ were labeled separately with Cy3 (red) and Cy5 (blue), respectively.

\subsubsection{2-DE protein pattern in classification of carcinoma cells}

High-resolution two-dimensional polyacrylamide gel electrophoresis (2-D PAGE) is a powerful research tool for the analytical separation of cellular proteins. The qualitative and quantitative pattern of polypeptides synthesized by a cell represents its phenotype and thus defines characteristics such as the morphology and the biological behavior of the cell. By analyzing and comparing the protein patterns of different cells, it is possible to recognize the cell type and to identify the most typical features of these cells. In applied pathology it is 
often difficult to identify the tissue of origin and the stage or grade of a neoplasia by cellular morphology analyzed by classical or immunostaining procedures. The protein pattern itself is the most characteristic feature of a cell and should therefore contribute to the identification of the cell type. For this reason, we separated protein fractions originating from different lung tumor cell lines using 2-D PAGE and we compared the resulting patterns on a multivariate statistical level using correspondence analysis (CA) and ascendant hierarchical clustering (AHC). The results indicate that (i) protein patterns are highly typical for cells and that (ii) the comparison of the protein patterns of a set of interesting cell types allows the identification of potentially new marker proteins. 2-D PAGE is thus a unique and powerful tool for molecular cytology or histopathology, unveiling the protein expression level of tissues or cells.

\subsubsection{2-DE in understanding Ovarian intratumoral heterogeneity}

The process of tumor progression leads to the emergence of multiple clones, and to the development of tumor heterogeneity. One approach to the study of the extent of such heterogeneity is to examine the expression of marker proteins in different tumor areas. Twodimensional gel electrophoresis (2-DE) is a powerful tool for such studies, since the expression of a large number of polypeptide markers can be evaluated. The tumor cells have been prepared from human ovarian tumors and analyzed by 2-DE and PDQUEST. As judged from the analysis of two different areas in each of nine ovarian tumors, the intratumoral variation in protein expression is low. In contrast, large differences have been observed when the protein profiles of different tumors are compared. The differences in gene expression between pairs of malignant carcinomas are slightly larger than the differences observed between pairs of benign tumors. Hence, the 2-DE analysis of intratumoral heterogeneity in ovarian cancer tissue indicates a low degree of heterogeneity.

\subsubsection{Strengths and weaknesses of 2D-PAGE}

Electrophoresis is an established technique that has undergone several advances that have enhanced resolution, detection, quantization, and reproducibility. The 2-D SDS-PAGE and 2DDIGE approaches to protein profiling are accessible and economical methods that possess high resolving power and enable the detection of hundreds of proteins on a single gel plate. Although reproducibility has been an issue with 2D-PAGE, especially when profiling two protein mixtures, it has been greatly improved with the use of 2D-DIGE. Resolution has been enhanced by the introduction of IPGs, which enable the analyst to tailor the $\mathrm{pH}$ gradient for maximum resolution using ultrazoom gels with a narrow $\mathrm{pH}$ gradient range. With modern 2D-PAGE, it is not unusual to resolve two proteins that differ in pI by $0.001 \mathrm{U}$. Although 2D-PAGE has been limited by its inability to resolve proteins that are too basic or too acidic, too large or too small, this limitation is continuously diminishing. For example, the separation of basic proteins can be analyzed using IPGs in the $\mathrm{pH}$ range of 4-12. Separation science is always evolving, and it will not be long before the remaining issues of gel electrophoresis are adequately resolved. The introduction of 2D-DIGE contributed immensely to solving problems of reproducibility and quantitation. The use of imagers and computers allows not only fast data mining, acquisition, and analysis but also spot detection, normalization, protein profiling, background correction, and reporting and exporting of data. As a separation, detection, and quantitation technique, 2D-DIGE is an 
important tool, especially for clinical laboratories involved in the determination of protein expression levels and disease biomarker discovery. When absolute biological variation between samples is the main objective, as in biomarker discovery, 2D-DIGE is the method of choice. While there has been significant progress in nongel (or solution-based) methods for coupling fractionation methods directly online with MS analysis, 2DPAGE has remained a popular technique for conducting proteomic studies. Though 2D-PAGE, like any fractionation scheme, has its advantages and disadvantages, there is no doubt that it will remain an essential technique for the characterization of proteomes for many years to come.

\subsubsection{Two-dimensional electrophoresis for cancer proteomics}

Proteome analysis is a direct measurement of proteins in terms of their presence and relative abundance (Wilkins et al., 1996). The overall aim of a proteomic study is characterization of the complex network of cell regulation. Neither the genomic DNA code of an organism nor the amount of mRNA that is expressed for each gene product (protein) yields an accurate picture of the state of a living cell (Lubec et al., 1999), which can be altered by many conditions. Proteome analysis is required to determine which proteins have been conditionally expressed, how strongly, and whether any posttranslational modifications are affected. Two or more different states of a cell or an organism (e.g., healthy and diseased tissue) can be compared and an attempt made to identify specific qualitative and quantitative protein changes. One of the greatest challenges of proteome analysis is the reproducible fractionation of these complex protein mixtures while retaining the qualitative and quantitative relationships. Currently, twodimensional polyacrylamide gel electrophoresis (2-D PAGE) is the only method that can handle this task (Cutler et al., 1999, Fegatella et al., 1999, Görg et al., 2000), and hence has gained special importance. Since 2-D PAGE is capable of resolving over 1,800 proteins in a single gel (Choe \& Lee, 2000), it is important as the primary tool of proteomics research where multiple proteins must be separated for parallel analysis. It allows hundreds to thousands of gene products to be analyzed simultaneously. In combination with computer assisted image evaluation systems for comprehensive qualitative and quantitative examination of proteomes, this electrophoresis technique allows cataloging and comparison of data among groups of researchers.

\section{Conclusion}

Two-dimensional gel electrophoresis and MALDI-MS are an effective strategy for determining the protein domains present in those gel spots that are observed at significantly lower MW values than are given in the database. While average sequence coverage is only $30 \%$, the peptides detected are confined to a specific region of the protein, such as the protein N- or Cterminal. This information could easily be incorporated into protein identification tables. Regional coverage information is not readily available from either LC-MS/MS analysis of digests of cellular lysates or from epitope-specific antibodies. Some of the protein fragments correspond to chains produced by known cellular processing and activation pathways. Others have been detected as functional and structural domains during in vitro experiments or noted in other in vivo studies, indicating they function intra- or extra-cellularly. By using tools that allow both protein identification and measurement of MW, we can assess the abundance and distribution of protein fragments. Correlation of these results with targeted functional studies on specific proteins will elucidate the biological function of protein fragments. 


\section{References}

Bae, SM., Lee, CH., Cho,YL., Nam, KH., Kim, YW., Kim, CK., Han, BD., Lee, YJ., Chun, HJ. \& Ahn, WS. (2005). Two-dimensional gel analysis of protein expression profile in squamous cervical cancer patients. Gynecologic Oncology 99: 26-35.

Bjellqvist, B., Ek, K., Righetti, PG., Gianazza, E., Gorg, A., Westermeier, R. \& Postel, W. (1982). Isoelectric focusing in immobilized $\mathrm{pH}$ gradients: principle, methodology and some applications, J Biochem Biophys Methods 6: 317-339.

Bjellqvist, B., Hughes, GJ., Pasquali, C., Paquet, N., Ravier, F., Sanchez, JC., Frutiger, S. \& Hochstrasser, D. (1993b). The focusing positions of polypeptides in immobilized $\mathrm{pH}$ gradients can be predicted from their amino acid sequences, Electrophoresis 14: 1023-1031.

Bjellqvist, B., Sanchez, JC., Pasquali, C., Ravier, F., Paquet, N., Frutiger, S., Hughes, GJ. \& Hochstrasser, D. (1993a). Micropreparative two-dimensional electrophoresis allowing the separation of samples containing milligram amounts of proteins, Electrophoresis 14: 1375-1378.

Carroll, K., Ray, K., Helm, B. \& Carey, E. (2000). Two-dimensional electrophoresis reveals differential protein expression in high- and low-secreting variants of the rat basophilic leukaemia cell line, Electrophoresis 21: 2476-2486.

Chevallet, M., Santoni, V., Poinas, A., Rouquie, D., Fuchs, A., Kieffer, S., Rossignol, M., Lunardi, J., Garin, J. \& Rabilloud, T. (1998). New zwitterionic detergents improve the analysis of membrane proteins by two-dimensional electrophoresis, Electrophoresis 19: 1901-1909.

Choe, LH. \& Lee, KH. (2000). A comparison of three commercially available isoelectric focusing units for proteome analysis: The multiphor, the IPGphor and the protean IEF cell, Electrophoresis 21: 993-1000.

Cordwell, SJ., Basseal, DJ., Bjellqvist, B., Shaw, DC. \& Humphery-Smith, I. (1997). Characterisation of basic proteins from Spiroplasma melliferum using novel immobilised pH gradients, Electrophoresis 18, 1393-1398.

Corthals,, GL., Wasinger, VC., Hochstrasser, DF. \& Sanchez, JC. (2000). The dynamic range of protein expression: a challenge for proteomic research, Electrophoresis 21: 1104-1115.

Cutler, P., Bell, DJ., Birrell, HC., Connelly, JC., Connor, SC., Holmes, E., Mitchell, BC., Monte, SY., Neville, BA., Pickford, R., Polley, S., Schneider, K. \& Skehel, JM. (1999). An integrated proteomic approach to studying glomerular nephrotoxicity, Electrophoresis 20: 3647-3658.

Ducret, A., Bruun, CF., Bures, EJ., Marhaug, G., Husby, G. \& Aebersold, R. (1996). Characterization of human serum amyloid A protein isoforms separated by twodimensional electrophoresis by liquid chromatography/electrospray ionization tandem mass spectrometry, Electrophoresis 17: 866-876.

Eckerskorn, C., Jungblut, P., Mewes, W., Klose, J. \& Lottspeich, F. (1988). Identification of mouse brain proteins after two-dimensional electrophoresis and electroblotting by microsequence analysis and amino acid composition analysis, Electrophoresis 9: 830838.

Fegatella, F., Ostrowski, M. \& Cavicchioli, R. (1999). An assessment of protein profiles from the marine oligotrophic ultramicrobacterium, Sphingomonas sp. Strain RB2256, Electrophoresis 20: 2094-2098.

Fountoulakis, M., Takacs, MF., Berndt, P., Langen, H. \& Takacs, B. (1999). Enrichment of low abundance proteins of Escherichia coli by hydroxyapatite chromatography, Electrophoresis 20: 2181-2195. 
Franzén, B., Linder, S., Alaiya, AA., Eriksson, E., Fujioka, K., Bergman, AC., Jörnvall, H. \& Auer, G. (1997). Analysis of polypeptide expression in benign and malignant human breast lesions. Electrophoresis 18: 582-587.

Garfin, DE. (1995). Electrophoretic methods, pp 53-109 in Glasel JA and Duetscher MP (eds) Introduction to Biophysical Methods for Protein and Nucleic Acid Research, Academic Press, San Diego.

Garfin, DE. (2000). Isoelectric focusing, pp 263-298 in Ahuja S (ed) Separation Science and Technology, Vol 2, Academic Press, San Diego.

Gingrich, JC. Davis, DR. \& Nguyen, Q. (2000). Multiplex detection of quantification of proteins on western blots using fluorescent probes, Biotechniques 29: 636-642.

Görg, A. (1991). Two-dimensional electrophoresis, Nature 349: 545-546.

Görg, A., Obermaier, C., Boguth, G. \& Weiss, W. (1999). Recent developments in twodimensional gel electrophoresis with immobilized $\mathrm{pH}$ gradients: wide $\mathrm{pH}$ gradients up to $\mathrm{pH} 12$, longer separation distances and simplified procedures, Electrophoresis 20: 712-717.

Görg, A., Obermaier, C., Boguth, G., Harder, A., Scheibe, B., Wildgruber, R. \& Weiss, W. (2000). The current state of two-dimensional electrophoresis with immobilized $\mathrm{pH}$ gradients, Electrophoresis 21: 1037-1053.

Görg, A., Postel, W., Domscheit, A. \& Günther, S. (1989) Methodology of two dimensional electrophoresis with immobilized $\mathrm{pH}$ gradients for the analysis of cell lysates and tissue proteins, in Endler AT and Hanash $S$ (eds) Two- Dimensional Electrophoresis. Proceedings of the International Two-Dimensional Electrophoresis Conference, Vienna, Nov. 1988, VCH, Weinheim FRG.

Gottlieb, M. \& Chavko, M. (1987). Silver staining of native and denatured eukaryotic DNA in agarose gels, Anal Biochem 165: 33-37.

Herbert, BR., Molloy, MP., Gooley, AA., Walsh, BJ., Bryson, WG. \& Williams, KL. (1998). Improved protein solubility in two-dimensional electrophoresis using tributyl phosphine as reducing agent, Electrophoresis 19: 845-851.

Hermann, T., Finkemeier, M., Pfefferle, W., Wersch, G., Kramer, R. \& Burkovski, A. (2000). Two-dimensional electrophoretic analysis of Corynebacterium glutamicu membrane fraction and surface proteins, Electrophoresis 21: 654-659.

Klose, J. (1975). Protein mapping by combined isoelectric focusing and electrophoresis of mouse tissues. A novel approach to testing for induced point mutation in mammals. Humangenetik 26, 231-243.

Lubec, G., Nonaka, M., Krapfenbauer, K., Gratzer, M., Cairns, N. \& Fountoulakis, M. (1999). Expression of the dihydropyrimidinase related protein 2 (DRP-2) in Down syndrome and Alzheimer's disease brain is downregulated at the mRNA and dysregulated at the protein level, J Neural Transm Suppl 57: 161-177.

Macri, J., McGee, B., Thomas, JN., Du, P., Stevenson, TI., Kilby, GW. \& Rapundalo, ST. (2000). Cardiac sarcoplasmic reticulum and sarcolemmal proteins separated by two-dimensional electrophoresis: surfactant effects on membrane solubilization, Electrophoresis 21: 1685-1693.

Masuoka, J., Glee, PM. \& Hazen, KC. (1998). Preparative isoelectric focusing and preparative electrophoresis of hydrophobic Candida albicans cell wall proteins with in-line transfer to polyvinylidene difluoride membranes for sequencing, Electrophoresis 19: 675-678.

Merril, CR., Goldman, D., Sedman, SA. \& Ebert, MH. (1981). Ultrasensitive stain for proteins in polyacrylamide gels shows regional variation in cerebrospinal fluid proteins, Science 211: 1437-1438. 
Miller, MJ. (1989). Computer-assisted analysis of two-dimensional gel electropherograms, pp 182-217 in Chrambach A, Dunn MJ and Radola BJ (eds) Advances in Electrophoresis, Vol. 3, Verlag Chemie, Weinheim.

Molloy, MP. (2000). Two-dimensional electrophoresis of membrane proteins using immobilized $\mathrm{pH}$ gradients, Anal Biochem 280: 1-10.

Molloy, MP., Herbert, BR., Walsh, BJ., Tyler, MI., Traini, M., Sanchez, JC., Hochstrasser, DF., Williams, KL. \& Gooley, AA. (1998). Extraction of membrane proteins by differential solubilization for separation using two-dimensional gel electrophoresis, Electrophoresis 19: 837-844.

Morel, V., Poschet, R., Traverso, V. \& Deretic, D. (2000). Towards the proteome of the rhodopsin-bearing post-Golgi compartment of retinal photoreceptor cells, Electrophoresis 21: 3460-3469.

Nilsson, CL., Larsson, T., Gustafsson, E., Karlsson, KA. \& Davidsson, P. (2000). Identification of protein vaccine candidates from Helicobacter pylori using a preparative twodimensional electrophoretic procedure and mass spectrometry, Anal Chem 72: 2148-2153.

O'Farrell, PH. (1975). High resolution two-dimensional electrophoresis of proteins. J Biol Chem 250, 4007-4021.

Patton, WF. (2000). A thousand points of light: the application of fluorescence detection technologies to two-dimensional gel electrophoresis and proteomics, Electrophoresis 21: 1123-1144.

Pennington, SR. \& Dunn, MJ. (2001). Proteomics. From Protein Sequence to Function, Springer/Bios, New York.

Rabilloud, T. (1998). Use of thiourea to increase the solubility of membrane proteins in twodimensional electrophoresis, Electrophoresis 19: 758-760.

Rabilloud, T. (1999). Solubilization of proteins in 2-DE. An outline, Methods Mol Biol 112: 9-19.

Rabilloud, T. (2000). Proteome Research: Two Dimensional Gel Electrophoresis and Identification Tools, Springer, Berlin.

Righetti, PG. (1983). Isoelectric Focusing: Theory, Methodology and Applications, Elsevier, Amsterdam.

Righetti, PG. (1990). Recent developments in electrophoretic methods, J Chromatogr 516: 3-22.

Sanchez, JC., Rouge, V., Pisteur, M., Ravier, F., Tonella, L., Moosmayer, M., Wilkins, MR. \& Hochstrasser, DF. (1997). Improved and simplified in-gel sample application using reswelling of dry immobilized $\mathrm{pH}$ gradients, Electrophoresis 18: 324-327.

Smithies, O. \& Poulik, MD. (1956). Two-Dimensional Electrophoresis of Serum Proteins. Nature 177, 1033.

Taylor, RS., Wu, CC., Hays, LG., Eng, JK., Yates, JR. \& Howell, KE. (2000). Proteomics of rat liver Golgi complex: minor proteins are identified through sequential fractionation, Electrophoresis 21: 3441-3459.

Wilkins, MR., Gasteiger, E., Sanchez, JC., Bairoch, A. \& Hochstrasser, DF. (1998). Twodimensional gel electrophoresis for proteome projects: the effects of protein hydrophobicity and copy number, Electrophoresis 19: 1501-1505.

Wilkins, MR., Sanchez, JC., Gooley, AA., Appel, RD., Humphery-Smith, I., Hochstrasser, DF. \& Williams, KL. (1996). Progress with proteome projects: Why all proteins expressed by a genome should be identified and how to do it. Biotechnol Genet Eng Rev 13: 19-50.

Wilkins, MR., Williams, KL; Appel, RD. \& Hochstrasser, DF. (1998). Proteome Research: New Frontiers in Functional Genomics, Springer, Berlin. 


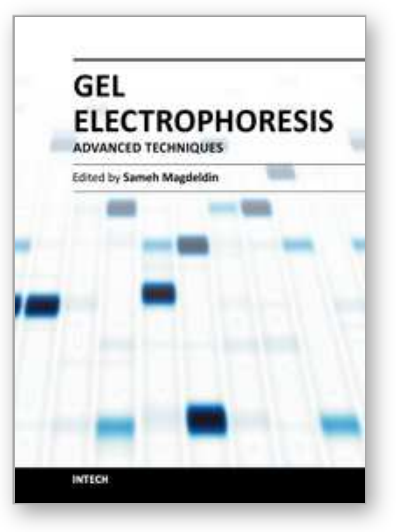

\author{
Gel Electrophoresis - Advanced Techniques \\ Edited by Dr. Sameh Magdeldin
}

ISBN 978-953-51-0457-5

Hard cover, 500 pages

Publisher InTech

Published online 04, April, 2012

Published in print edition April, 2012

As a basic concept, gel electrophoresis is a biotechnology technique in which macromolecules such as DNA, RNA or protein are fractionated according to their physical properties such as molecular weight or charge. These molecules are forced through a porous gel matrix under electric field enabling uncounted applications and uses. Delivered between your hands, a second book of this Gel electrophoresis series (Gel Electrophoresis- Advanced Techniques) covers a part, but not all, applications of this versatile technique in both medical and life science fields. We try to keep the contents of the book crisp and comprehensive, and hope that it will receive overwhelming interest and deliver benefits and valuable information to the readers.

\title{
How to reference
}

In order to correctly reference this scholarly work, feel free to copy and paste the following:

Soundarapandian Kannan, Mohanan V. Sujitha, Shenbagamoorthy Sundarraj and Ramasamy Thirumurugan (2012). Two Dimensional Gel Electrophoresis in Cancer Proteomics, Gel Electrophoresis - Advanced Techniques, Dr. Sameh Magdeldin (Ed.), ISBN: 978-953-51-0457-5, InTech, Available from: http://www.intechopen.com/books/gel-electrophoresis-advanced-techniques/2-d-gel-electrophoresis-in-cancerproteomics

\section{INTECH}

open science | open minds

\section{InTech Europe}

University Campus STeP Ri

Slavka Krautzeka 83/A

51000 Rijeka, Croatia

Phone: +385 (51) 770447

Fax: +385 (51) 686166

www.intechopen.com

\section{InTech China}

Unit 405, Office Block, Hotel Equatorial Shanghai

No.65, Yan An Road (West), Shanghai, 200040, China

中国上海市延安西路65号上海国际贵都大饭店办公楼405单元

Phone: +86-21-62489820

Fax: $+86-21-62489821$ 
(C) 2012 The Author(s). Licensee IntechOpen. This is an open access article distributed under the terms of the Creative Commons Attribution 3.0 License, which permits unrestricted use, distribution, and reproduction in any medium, provided the original work is properly cited. 